\title{
EL DERECHO A LA PRIVACIDAD EN LOS ESTADOS UNIDOS: APROXIMACIÓN DIACRÓNICA A LOS INTERESES CONSTITUCIONALES EN JUEGO
}

\author{
MARÍA NIEVES SALDAÑA \\ Profesora Contratada-Doctora \\ Universidad de Huelva
}

SUMARIO.

I. Introducción.

II. Emergencia de la protección constitucional de la privacidad: «The right to be let alone» y la Cuarta Enmienda.

III. La «inducción» constitucional del derecho fundamental a la privacidad: la «libertad sustantiva» de la Decimocuarta Enmienda.

IV. La protección de la privacidad en la sociedad tecnológica: el derecho constitucional a la «informational privacy».

V. Consideraciones finales: la «fundamentalidad» de la privacidad para el sistema democrático.

\section{INTRODUCCIÓN}

La emergencia de la protección de la esfera privada en el sistema jurídico norteamericano data de finales del siglo XIX, cuando fue abordado en algunos escritos doctrinales que sentaron las bases para su configuración posterior ${ }^{1}$. Aunque, sin duda, la paternidad del derecho a la privacidad en el sistema jurídico norteamericano se atribuye generalmente a los célebres abogados de Boston, Samuel D. Warren y Louis D. Brandeis, quienes reformularon la expresión «the right to be let alone» en un estudio publicado en di-

1 Sobre la protección de la privacidad en la Norteamérica decimonónica, vid. Note: «The Right to Privacy in Nineteenth Century America», Harvard Law Review, vol. 94, 1981, págs. 1892-1910. Para el periodo colonial y con carácter más general, vid. también FLAHERTY, D. H., Privacy in Colonial New England, University Press of Virginia, Charlottesville, 1972; O'CONNOR, TH. H., «The Right to Privacy in Historical Perspective», Massachusetts Law Review, vol. 53, 1968, págs. 101 y ss. 
ciembre de 1890 en la Harvard Law Review con el título "The Right to Privacy», cuando reaccionaban frente a la divulgación indiscriminada por la prensa de información privada y afirmaban que impedir su publicación es solo un ejemplo del derecho más general del individuo a no ser molestado (the more general right of the individual to be let alone), defendiendo un «right to privacy» que le otorga a toda persona plena disponibilidad para decidir en qué medida "pueden ser comunicados a otros sus pensamientos, sentimientos y emociones» ${ }^{2}$. Desde entonces y a lo largo de todo el siglo XX, la protección de la esfera privada en los Estados Unidos ha pasado del ámbito del common law al propio del Derecho constitucional, como consecuencia de su evolución desde una noción propietaria de la privacidad (privacy-property) a una concepción estrechamente relacionada con la dignidad de la persona, consolidándose como un bien jurídico fundamental merecedor de la máxima protección en el sistema constitucional norteamericano ${ }^{3}$.

En efecto, aunque ni la Constitución Federal de 1787 ni sus Enmiendas reconocen expresamente un «right to privacy», sin embargo, como se analiza en el presente estudio, el Tribunal Supremo, a lo largo de una extensa y gradual jurisprudencia, lo ha considerado implícito en la libertad de asociación garantizada por la Primera Enmienda, que salvaguarda frente a cualquier obligación estatal de revelar la pertenencia a un grupo u organización ${ }^{4}$; en la garantía de la Cuarta Enmienda frente a registros y requisas arbitrarias (unreasonable searches and seizures), que limita la intrusión del gobierno en las personas, domicilios, documentos y efectos personales, incluyéndose no sólo los supuestos de invasión material (physical trespass) sino también de vigilancia electrónica ; en la Quinta Enmienda, que protege frente a la incriminación contra uno mismo y la obligación de revelar información personal ${ }^{6}$; en la reserva de derechos del pueblo que reconoce la Nove-

2 Vid. WARREN, S. y BRANDEIS, L. D., «The Right to Privacy», Harvard Law Review, vol. 4, núm. 5, 1890, págs. 193-220, especialmente págs. 198 y 205. El artículo ha sido publicado en español bajo el título El derecho a la intimidad, Editorial Civitas, Madrid, 1995, especialmente págs. 31 y 44. De la extensa literatura estudiosa del célebre artículo, vid. BRATMAN, B. E., «Brandeis and Warren's The Right to Privacy and The Birth of The Right to Privacy», Tennessee Law Review, vol. 69, 2002, págs. 623-651; BARRON, J. H., "Warren and Brandeis, 'The Right to Privacy', 4 Harvard Law Review, 193 (1890): Demystifying a Landmark Citation», Suffolk University Law Review, vol. 13, 1979, págs. 875 y ss.; GLANCY, D. J., «The Invention of the Right to Privacy», Arizona Law Review, vol. 21, núm. 1, 1979, págs. 1-39.

3 GORMLEY, K., «One Hundred Years of Privacy», Wisconsin Law Review, 1992, págs. 1335-1441.

4 «El Congreso no hará ley alguna con respecto a la adopción de una religión o prohibiendo la libertad de cultos; o que restrinja la libertad de expresión o de prensa, o el derecho del pueblo a reunirse pacíficamente y a solicitar al gobierno la reparación de agravios», I Enmienda a la Constitución de los Estados Unidos (1791). Vid. NAACP v. Alabama, 357 U.S. 449 (1958); Shelton v. Tucker, 364 U.S. 479 (1960); Bates v. City of Little Rock, 361 U.S. 516 (1960); Gibson v. Florida Legislative Investigating Committee, 372, U.S. 539 (1963) y NAACP v. Alabama ex rel. Flowers, 377 U.S. 288 (1964).

5 «El derecho del pueblo a la seguridad de sus personas, hogares, documentos y pertenencias frente a allanamientos y registros arbitrarios será inviolable, y no se expedirá ningún mandamiento, sino en virtud de causa probable, apoyado en juramento o promesa, que describa el lugar que ha de ser registrado y las personas o cosas que han de ser detenidas o incautadas», IV Enmienda a la Constitución de los Estados Unidos (1791). De la abundante jurisprudencia, vid. Olmstead v. United States, 277 U.S. 438 (1928); Goldman v. United States, 316 U.S. 129 (1942); Lee v. United States, 343 U.S. 747 (1952); Irvine v. California, 347 U.S. 128 (1954); Map v. Ohio, 367 U.S. 643, 656 (1961); Silverman v. United States, 365 U.S. 505 (1961); Osborn v. United States, 385 U.S. 323 (1966); Katz v. United States, 389 U.S. 347 (1967) y Kyllo v. United States, 533 Ü.S. 27 (2001).

6 «Ninguna persona [...] será obligada a declarar contra sí misma en ningún proceso penal, ni será privada de su vida, su libertad o propiedad sin el debido proceso legal», V Enmienda a la Constitución de los 
na Enmienda ${ }^{7}$; y en el concepto de libertad sustantiva que el Tribunal Supremo ha interpretado ampara la cláusula del debido proceso legal (due process of law) de la Decimocuarta Enmienda, que garantiza el derecho de la persona a adoptar por sí misma las decisiones fundamentales que configuran su vida personal y familiar sin injerencia estatal alguna, incluyéndose el derecho a contraer matrimonio, a tener hijos y decidir sobre la educación y crianza de éstos, al uso de anticonceptivos, el derecho al aborto y a la libertad sexual en el ámbito privado, planteándose incluso si la cláusula del debido proceso ampara el derecho a rechazar un tratamiento médico ${ }^{8}$ y, finalmente, en la década de los sesenta emerge una jurisprudencia vacilante que tiende a incluir en la zona de privacidad protegida constitucionalmente por el concepto de libertad de la Decimocuarta Enmienda el interés individual en evitar la divulgación de información personal, la llamada «informational privacy»? .

Así, en el sistema constitucional norteamericano el derecho a la privacidad es un concepto amplio, que va más allá del derecho a la intimidad vigente en el ámbito europeo $^{10}$, difícil de definir con precisión y que se ha configurado a lo largo de más de un siglo al delimitarse progresivamente los intereses constitucionales que lo integran, esto es, aquellos ámbitos de la esfera privada que tienden a preservar esos intereses de soledad, secreto, autonomía, individualidad, intimidad, desarrollo de la personalidad, libertad de elección en asuntos personales, control de la información personal, así como del sustrato esencial de la inviolable dignidad humana ${ }^{11}$. Múltiples intereses individuales de carácter esencial que lo hacen merecedor de la máxima protección constitucional en la sociedad

Estados Unidos (1791). Vid. especialmente Boyd v. United States, 116 U.S. 616, 630 (1886); Gouled v. United States, 255 U.S. 298 (1921).

7 «La enumeración en la Constitución de ciertos derechos, no ha de interpretarse para negar o menospreciar otros que retiene el pueblo», IX Enmienda a la Constitución de los Estados Unidos (1791). Vid. especialmente Griswold v. Connecticut, 381 U.S. 479, 484-485 (1965) (Goldberg, A. J., concurring).

8 « [... Ningún Estado podrá privar a una persona de la vida, la libertad o la propiedad sin el debido proceso legal», XIV Enmienda a la Constitución de los Estados Unidos, Sección 1 (1868). De la extensa jurisprudencia, vid. Loving v. Virginia, 388 U.S. 1 (1967); Skinner v. Oklahoma ex rel. Williamson, 316 U.S. 535 (1942); Meyer v. Nebraska, 262 U.S. 390 (1923); Pierce v. Society of Sisters, 268 U.S. 510 (1925); Griswold v. Connecticut, 381 U.S. 479 (1965); Eisenstadt v. Baird, 405 U.S. 438 (1972); Roe v. Wade, 410 U.S. 113 (1973); Planned Parenthood of Southeastern Pennsylvania v. Casey, 505 U.S. 833 (1992); Lawrence et al. v. Texas, 539 U.S. 558 (2003); Cruzan v. Director, Missouri Dep't. of Health, 497 U.S. 261 (1990); Washington v. Glucksberg, 521 U.S. 702, 720 (1997).

9 Vid. Whalen v. Roe, 429 U.S. 589, 599-600, 605 (1977); Nixon v. Administrator of General Services, 433 U.S. 425, 457 (1977); Nelson v. NASA, 506 F.3d 713, 715-16 (9th Cir. 2007); National Aeronautic and Space Administration et al. v. Nelson et al., 131 S. Ct. 746 (2011).

$10 \mathrm{Al}$ respecto, vid. WHITMAN, J. Q., «The Two Western Culture of Privacy: Dignity versus Liberty», Yale Law Journal, vol. 113, 2004, págs. 1151-1221.

11 De la extensa literatura, vid. SOLOVE, D. J., «Conceptualizing privacy», California Law Review, vol. 90, 2002, págs. 1087-1155; POST, R. C., «Three Concepts of Privacy», Georgetown Law Journal, vol. 89, 2001, págs. 2087-2098; BENZANSON, R. P., «The Right to Privacy Revisited: Privacy, News, and Social Change, 1890-1990», California Law Review, vol. 80, 1992, págs. 1133-1175; Rubenfeld, J., «The Right of Privacy», Harvard Law Review, vol. 102, 1989, págs. 737-807; GAVISON, R., «Privacy and the Limits of Law», The Yale Law Journal, vol. 89, 1980, págs. 421 y ss.; GereTY, T., «Redefining Privacy», Harvard Civil Rights-Civil Liberty Law Review, vol. 12, 1977, págs. 233 y ss.; Craven, B., «Personhood: The Right to Be Let Alone», Duke Law Journal, vol. 15, 1976, págs. 699-720; Bloustern, E., «Privacy as an Aspect of Human Dignity: an Answer to Dean Prosser», New York University Law Review, vol. 39, 1964, págs. 962-1007. 
tecnológica avanzada de principios del siglo XXI, configurándose, en última instancia, el derecho a la privacidad como un bien jurídico fundamental para la esencia misma del sistema democrático.

\section{EMERGENCIA DE LA PROTECCIÓN CONSTITUCIONAL DE LA PRIVACIDAD: «THE RIGHT TO BE LET ALONE»Y LA CUARTA ENMIENDA}

Como se apuntó más arriba, la expresión «the right to be let alone» fue inicialmente acuñada en 1879 por el juez Thomas M. Cooley en la primera edición de su Treatise on the Law of Torts ${ }^{12}$, habiendo esgrimido también Cooley en otro Tratado anterior las garantías de la Cuarta y Quinta Enmiendas como vehículos de protección de la esfera privada de la persona ${ }^{13}$. Sin duda, en la concepción de Cooley está presente el principio básico heredado del Derecho inglés «a man's house as his castle» (la casa de cada uno es su castillo), que confiere al hogar del individuo la máxima protección personal ${ }^{14}$. Principio que en 1791 había alcanzado expreso reconocimiento constitucional en la garantía de la Tercera Enmienda de la Constitución norteamericana, que prohíbe la confiscación de domicilios particulares por los soldados sin el consentimiento de su propietario en tiempos de paz ${ }^{15}$, en la garantía de la Cuarta Enmienda, que protege a los ciudadanos frente a registros y requisas arbitrarios o injustificados (unreasonable searches and seizures), limitando la intrusión del Gobierno en las personas, domicilios, documentos y efectos personales ${ }^{16}$, así como, de forma indirecta, en la Quinta Enmienda, que salvaguarda frente a la incri-

12 «El derecho de la persona se dice que es el derecho a la completa inmunidad; el derecho a ser dejado solo», COOLEY, TH. M., A Treatise on the Law of Torts or the Wrongs Which Arise Independently of Contract, Callaghan, Chicago, 1879, pág. 29.

13 COOLEY, TH. M., A Treatise on the Constitutional Limitations which Rest upon the Legislative Power of the States of the American Union, Little, Brown, and Co., Boston, 1868, págs. 305 y 578.

14 El principio «a man's house as his castle» fue paradigmáticamente formulado por William Pitt en el conocido discurso que pronunciara ante el Parlamento de Inglaterra en 1763, invocando la célebre máxima para reivindicar la protección personal del individuo frente al poder del Monarca incluso en la más humilde morada, «El hombre más pobre, en su cabaña, desafía todas las fuerzas de la Corona. [Su cabaña] puede ser frágil, su techo tal vez es inestable, el viento se cuela por él, la tempestad lo penetra, no impide el paso de la lluvia, pero el Rey de Inglaterra no puede entrar en ella; ni con todo su poder se atreve a cruzar el umbral de esa ruinosa morada», PITT, W., «Speech on the Excise Bill», vid. The Parliamentary History of England from the Earliest Period to the Year 1803, 23 vols., T. C. HANSARD (ed.), London, 1806-1820, vol. 15 (1753-1765), pág. 1307.

15 «En tiempos de paz, ningún soldado será alojado en vivienda alguna sin el consentimiento del propietario; ni tampoco lo será en tiempos de guerra, salvo en la forma que prescriba la ley», III Enmienda a la Constitución de los Estados Unidos (1791).

16 Inicialmente, la Cuarta Enmienda se establece como una garantía de la libertad y seguridad personal frente a los llamados «Writs of Assistance», mandatos generales otorgados por el Parlamento a las autoridades coloniales que autorizaban la entrada, registro y requisa de bienes y efectos, así como detenciones de personas, de los numerosos estudios, vid. LASSON, N. B., The History and Development of the Fourth Amendment to the United States, Johns Hopkins University Press, Baltimore, 1937; LANDYNSKI, J. B., Search and Seizure and the Supreme Court: Study in Constitutional Interpretation, Johns Hopkins University Press, Baltimore, 1966; DAVIES, Th. Y., «Recovering the Original Fourth Amendment», Michigan Law Review, núm. 98, 1999, págs. 547-750; Clancy, Th. K., The Fourth Amendment: Its History and Interpretation, Carolina Academic Press, Durham, 2008. 
minación contra uno mismo e impide que el Gobierno le obligue a revelar información personal y reservada ${ }^{17}$.

Así, uno de los juristas más influyentes del período posterior a la Guerra Civil norteamericana, el juez Thomas M. Cooley, afirmaba en la primera edición de su Tratado de Derecho Constitucional, A Treatise on the Constitutional Limitations which Rest upon the Legislative Power of the States of the American Union (1868), que las garantías de la Tercera, Cuarta y Quinta Enmiendas constituyen vehículos de protección de la esfera individual, señalando que la máxima del common law «a man's house as his castle», que garantiza la inmunidad del ciudadano en su domicilio frente a la acción del Gobierno y la protección de su persona, propiedad y documentación personal, formaba parte del Derecho constitucional norteamericano a través de la cláusula de la Cuarta Enmienda que prohíbe registros y requisas injustificadas de personas y domicilios ${ }^{18}$. Incluso, Cooley establecía una suerte de «bisagra de privacidad» que ensambla la Cuarta y Quinta Enmiendas, afirmando que no es admisible invadir la esfera privada del domicilio con el sólo propósito de obtener evidencias frente a su titular ${ }^{19}$.

Y en 1879, once años antes del célebre artículo de Warren y Brandeis, el mismo Thomas L. Cooley acuñaba la expresión «the right to be let alone» en la primera edición de su Treatise on the Law of Torts, «el derecho de la persona se dice que es el derecho a la completa inmunidad; a ser dejado solo» ${ }^{20}$. Y al analizar los supuestos de violación de la Cuarta y Quinta Enmiendas en los casos de registros y requisas ilegales del domicilio con el objetivo de obtener evidencias suficientes para el procesamiento del acusado, Cooley afirmaba que el derecho del individuo a protegerse frente a invasiones de su esfera privada alcanza tanto frente a la intromisión ilegal de los agentes del Gobierno como frente a la curiosidad lasciva del público en general ${ }^{21}$.

Tan sólo seis años más tarde, en 1886, el Tribunal Supremo norteamericano acogió expresamente la argumentación de Cooley en el caso Boyd v. United States, considerando que la aprehensión de documentos privados, previo requerimiento, y su utilización como evidencia probatoria es contrario a la Cuarta y Quinta Enmiendas. Así, al expresar la opinión del Tribunal, el juez Bradley retoma la máxima inglesa «bome is your castle» para declarar «the sanctity of a man's home and the privacies of life», conectando por primera vez las garantías de la Cuarta y Quinta Enmiendas frente a la invasión gubernamental del ámbito privado para obtener información reservada de la persona a través del registro ilegal de su domicilio al objeto de utilizarla como evidencia contra ella ${ }^{22}$.

17 «Ninguna persona [...] será obligada a declarar contra sí misma en ningún proceso penal, ni será privada de su vida, su libertad o sus bienes sin el debido proceso legal», V Enmienda a la Constitución de los Estados Unidos (1791).

18 Cfr. CoOley, Thomas M., A Treatise on the Constitutional Limitations which Rest upon the Legislative Power of the States of the American Union, op. cit., págs. 299-300.

19 Ibídem, págs. 305 y 578.

20 CoOley, Th. M., A Treatise on the Law of Torts or the Wrongs Which Arise Independently of Contract, Callaghan, Chicago, 1879, pág. 29.

21 Ibídem, pág. 294.

22 «a esencia misma de la libertad y seguridad constitucional se ve afectada ante cualquier invasión por parte del gobierno y de sus agentes de la santidad del hogar de la persona y de la privacidad de su vida. No es la rotura de sus puertas, o el registro de sus cajones lo que constituye la esencia del delito, sino la invasión de su inderogable derecho a la libertad y seguridad personal y a la propiedad privada», Boydv. United States, 116 U.S. 616, 630 (1886). Vid. Note, «The Life and Times of Boydv. United States (1886-1976)», Michigan Law Review, vol. 76, 1977, págs. 184-212. 
Sin embargo, basándose en la dominante concepción propietaria de los derechos consignados en la Cuarta Enmienda ${ }^{23}$, durante la primera mitad del siglo XX el Tribunal Supremo adoptó una interpretación muy literal de las garantías frente a registros arbitrarios, exigiéndose una efectiva intrusión física (phisical trespass) en los domicilios, documentos y efectos personales ${ }^{24}$. Como cabía esperar, frente a esta concepción estrictamente material de las garantías de la Cuarta y Quinta Enmiendas se opuso Louis D. Brandeis, defendiendo en su célebre voto discrepante del caso Olmstead v. United States los mismos argumentos que había avanzado cuarenta años antes en las últimas líneas de su ensayo "The Right to Privacy» ${ }^{25}$, invocando el derecho a ser dejado solo (the right to be let alone) para fundamentar que las garantías de la Cuarta y Quinta Enmiendas amparan constitucionalmente el derecho a la privacidad ${ }^{26}$.

En 1928 el Tribunal Supremo estadounidense resolvió por supuesta violación de la Cuarta y Quinta Enmiendas el caso Olmstead $v$. The United States, sobre escuchas y registro de conversaciones telefónicas practicadas durante cinco meses por oficiales del Gobierno de las actividades de comerciantes sospechosos de violar la National Probibition Act de 1920 mediante la importación, el almacenamiento y la venta de bebidas alcohólicas. La opinión mayoritaria del Tribunal, expresada por el juez William Howard Taft, no consideró las escuchas telefónicas una violación de la prohibición de la Cuarta Enmienda de practicar registros y requisas arbitrarias o injustificadas (unreasonable searches and seizures). Basándose en una serie de casos previos ${ }^{27}$, la mayoría del Tribunal defendió una interpretación estricta de la Cuarta Enmienda, afirmando que la prohibición se refiere al registro de cosas materiales - la persona, la casa, la documentación y los efectos personales- y en el caso no hubo registro, no se penetró en las casas ni en las oficinas de los imputados, se obtuvo la evidencia mediante escuchas telefónicas. En su fundamentación, Taft afirma que quienes instalan en su domicilio un instrumento telefónico con cables que lo conectan al exterior se proponen proyectar su voz hacia quienes están fuera, y que tal cableado y los mensajes que conducen no están protegidos por la Cuarta Enmienda, de ahí que el Tribunal concluya, igualmente, que la presentación como prueba de las grabaciones telefónicas practicadas no constituye una violación de la garantía de no incriminación contra uno mismo que reconoce la Quinta Enmienda ${ }^{28}$.

23 Vid. Clancy, Th. K., «What Does the Fourth Amendment Protect: Property, Privacy, or Security?», Wake Forest Law Review, vol. 33, 1998, págs. 307-370, especialmente págs. 309-327; ClOuD, M., «The Fourth Amendment During the Lochner Era: Privacy, Property and Liberty in Constitutional Theory», Stanford Law Review, vol. 48, 1996, págs. 555-631; BARret, E. L., «Personal Rights, Property Rights, and the Fourth Amendment», Supreme Court Review, 1960, págs. 46-74.

24 De la abundante jurisprudencia, vid. Gouled v. United States, 255 U.S. 298 (1921); Hester v. United States, 265 U.S. 57 (1924); Olmstead v. United States, 277 U.S. 438 (1928); Goldman v. United States, 316 U.S. 129 (1942); y Lee v. United States, 343 U.S. 747 (1952).

25 Warren, S. y BrandeIs, L. D., El derecho a la intimidad, op. cit., págs. 72 y 73 . Para la edición original, vid. «The Right to Privacy», op. cit., pág. 220.

26 Olmstead v. United States, 277 U.S. 438, 478, 479 (1928) (Brandeis, J., dissenting).

27 Vid. Gouled v. United States, 255 U.S. 298 (1921); Silverthome Lumber Co., v. United States, 251 U.S. 385 (1920); Agnello v. United States, 269 U.S. 57 (1924); y Weeks v. United States, 232 U.S. 383 (1914).

28 «La enmienda no prohíbe lo que aquí se hizo. No hubo registro. No hubo incautación. La prueba fue obtenida por el uso del sentido del oído y sólo eso. No hubo entrada en las casas u oficinas de los acusados [...] Las palabras de la Enmienda no pueden extenderse y ampliarse para incluir cables telefónicos [...] Los cables intervenidos no son parte de su casa y oficina, no más de lo que lo son las carreteras por las que son tendidos [...] 
Sin embargo, Louis D. Brandeis, entonces magistrado del Tribunal Supremo de los Estados Unidos, se apartó de la interpretación literal de la Cuarta Enmienda en uno de sus votos discrepantes más célebres, reivindicando una interpretación dinámica de la Constitución que permita adaptar las garantías constitucionales individuales establecidas frente a los abusos del poder a los cambios operados en los ámbitos político y social. Al igual que hiciera treinta y siete años antes en «The Right to Privacy», Brandeis manifestó una gran preocupación frente a los avances tecnológicos invasivos de la privacidad, especialmente aquellos que podían interceptar las comunicaciones por cable, afirmando que la interceptación de la comunicación telefónica es mucho peor que la de la correspondencia, por cuanto que cuando se intercepta una línea de teléfono se invade la privacidad en ambos extremos de la línea. En su argumentación, Brandeis afirma que frente al poder coactivo del Gobierno los autores de la Constitución otorgaron al pueblo norteamericano «the right to be let alone», el más amplio de los derechos y el más valioso para el hombre civilizado, de ahí que toda intromisión injustificada del Gobierno en la esfera privada de la persona, cualesquiera que fuesen los medios utilizados, constituya —a juicio de Brandeis - una violación de la Cuarta Enmienda y, en consecuencia, la utilización como prueba de hechos revelados por esa intromisión constituya, asimismo, una violación de la Quinta Enmienda ${ }^{29}$.

Igualmente, Brandeis denuncia la potencial invasión estatal de la esfera privada por avanzados dispositivos de reproducción o grabación, argumentando que el descubrimiento y la invención de mecanismos más sutiles y de mayor capacidad de invasión de la privacidad permitirían al Gobierno asaltar la esfera personal individual, revelándose en los tribunales lo que es susurrado en la intimidad. Para reforzar su argumentación, Brandeis insiste en los peligros que las futuras tecnologías a disposición del Estado podrían suponer para una efectiva protección de la privacidad, sentenciado para la posteridad en su voto particular discrepante de Olmstead $v$. United States la perpetua dependencia de la protección de la privacidad de los emergentes avances tecnológicos. En definitiva, Brandeis defiende una interpretación abierta y dinámica de la Cuarta Enmienda, considerando que las previsiones constitucionales encarnan principios generales y que

La opinión razonable es que quien instala en su casa un instrumento telefónico conectado con cables pretende proyectar su voz por ellos hacia afuera, y que los cables fuera de su casa y los mensajes mientras que pasan por ellos no están dentro de la protección de la Cuarta Enmienda [...] Creemos, por tanto, que la interceptación telefónica aquí revelada no equivale a un registro o incautación en el sentido de la Cuarta Enmienda», Olmstead v. United States, 277 U.S. 438, 465, 466 (1928).

29 «Siempre que una línea telefónica está intervenida, la privacidad de las personas que hablan en ambos extremos de ella es invadida y todas sus conversaciones sobre cualquier tema, por muy íntimas, confidenciales o privilegiadas que sean, pueden ser escuchadas por otros [...] Los autores de nuestra Constitución se propusieron garantizar las condiciones propicias para la búsqueda de la felicidad. Reconocieron la importancia del carácter espiritual del hombre, sus sentimientos y su intelecto. Sabían que en las cosas materiales sólo se puede hallar una parte del dolor, el placer y las satisfacciones de la vida. Trataron de proteger a los estadounidenses en sus creencias, ideas, emociones y sensaciones. Otorgaron frente al gobierno el derecho a ser dejado soloel más completo de los derechos, y el más apreciado por el hombre civilizado. Para proteger ese derecho, toda intrusión no justificable del gobierno en la vida privada del individuo, cualquiera que sean los medios empleados, debe considerarse una violación de la Cuarta Enmienda. Y la utilización como prueba en un proceso penal de hechos averiguados por esa intrusión debe considerarse una violación de la Quinta Enmienda», Olmstead v. United States, 277 U.S. 438, 478, 479 (1928) (Brandeis, J., dissenting). 
constituye obligación de cada generación decidir la mejor manera de realizar esos principios a luz de sus circunstancias vigentes.

La interpretación de Brandeis resultó ser muy adelantada a su tiempo. En efecto, la opinión mayoritaria del Tribunal Supremo en Olmstead v. United States sería confirmada en su jurisprudencia de las próximas cuatro décadas. Así, aunque en 1949, en el caso Wolfv. Colorado, se afirmó que la seguridad de la privacidad frente a una intrusión arbitraria por los agentes policiales es el núcleo de la Cuarta Enmienda y básico para una sociedad libre, que está implícito en el concepto de libertad y por tanto exigible a los Estados a través de la cláusula del debido proceso legal (due proces clause) de la Decimocuarta Enmienda ${ }^{30}$, sin embargo, en casos posteriores, como Goldman v. United States, Lee v. United States, e Irvine v. California, entre otros, se mantuvo la concepción de que la infracción de la Cuarta Enmienda sólo tiene lugar cuando se produce una invasión física de la propiedad individual o una inspección material de efectos personales, habilitándose así a los agentes del Gobierno a utilizar mecanismos de vigilancia electrónica que, como los dictáfonos y micrófonos, no exigen la irrupción física en las propiedades o efectos personales de los ciudadanos $^{31}$.

Hasta la década de los 60 no se inicia una jurisprudencia más favorable a una interpretación más abierta del bien constitucionalmente protegido por la garantía de la Cuarta Enmienda, centrándose en el derecho a la privacidad ${ }^{32}$. En efecto, ya en 1961 el Tribunal Supremo declaró expresamente en Mapp v. Obio que la Cuarta Enmienda genera un derecho a la privacidad no menos importante que cualquier otro derecho especialmente reservado al pueblo, siendo por tanto exigible a los Estados a través de la cláusula del debido proceso legal (due process clause) de la Decimocuarta Enmienda ${ }^{33}$. Ese mismo año, la orientación del Tribunal Supremo en Silverman v. United States parece iniciar un cambio progresivo hacía una concepción más favorable a la protección de la privacidad bajo la Cuarta Enmienda. Aunque la mayoría del Tribunal descansó en el clásico supuesto de invasión material (physical trespass), no admitiendo la instalación de un micro en la pared de una vivienda que controlaba todas las conversaciones habidas en su interior por considerar que constituía una invasión material de la misma, sin embargo, en su voto particular concurrente, el juez Douglas rogaba al Tribunal que superase ya la noción de invasión material de la Cuarta Enmienda y analizara si la privacidad del hogar había sido invadida ${ }^{34}$.

En los casos posteriores a Silverman, especialmente en Hoffa v. United States ${ }^{35}$, Lewis v. United States ${ }^{36}$ y Osborn v. United States ${ }^{37}$, se demandó reiteradamente la superación de la

30338 U.S. 25, 27 (1949). Es doctrina que se reitera en Mapp v. Obio, 367 U.S. 643 (1961); Ker v. California, 374 U.S. 23 (1963); Stamford v. Texas, 379 U.S. 476 (1965); y Camera v. Municipal Court, 387 U.S. 523 (1967).

31 Vid. Goldman v. United States, 316 U.S. 129 (1942), Lee v. United States, 343 U.S. 747, 753-754 (1952), e Irvine v. California, 347 U.S. 128 (1954).

32 Especialmente en Silverman v. United States, 365 U.S. 505 (1961); Mapp v. Ohio, 367 U.S. 643 (1961); Osborn v. United States, 385 U.S. 323 (1966); Warden v. Hayden, 387 U.S. 294 (1967); Berger v. United States, 388 U.S. 41 (1967) y Katz v. United States, 389 U.S. 347 (1967).

33367 U.S. 643,656 (1961).

34365 U.S. 505, 513 (1961) (Douglas, J., dissenting).

35385 U.S. 293 (1966).

36385 U.S. 206 (1966).

37385 U.S. 323 (1966).

UNED. Teoría y Realidad Constitucional, núm. 28, 2011, pp. 279-312. 
noción de invasión material y la garantía efectiva de un derecho a la privacidad constitucionalmente protegido bajo la Cuarta Enmienda. Destaca especialmente la argumentación ofrecida por el juez Douglas en su voto particular del caso Osborn v. United States, en el que se admitió como prueba incriminatoria la grabación mediante dispositivos ocultos, previo mandato judicial, de las declaraciones hechas por un abogado — que trata de corromper a un jurado - a un agente federal secreto (bugging). Douglas considera que tales pruebas judiciales transgreden los estándares constitucionales de la Cuarta Enmienda, afirmando el carácter fundamental que tienen las distintas zonas de privacidad para garantizar la existencia de una sociedad libre ${ }^{38}$.

En 1967, el Tribunal Supremo afirma en Camara v. Municipal Court que el propósito básico de la Cuarta Enmienda es salvaguardar la privacidad y seguridad de las personas frente a intrusiones arbitrarias por funcionarios gubernamentales ${ }^{39}$. En junio de ese mismo año, en Berger v. New York, el Tribunal declaró inconstitucional, por violación de la Cuarta Enmienda una ley de Nueva York que autorizaba la grabación secreta de comunicaciones por agentes encubiertos por períodos de hasta sesenta días, afirmando que las conversaciones estaban protegidas por la Cuarta Enmienda y que el uso de artefactos electrónicos para incautarlas no determina que fuesen registros constitucionalmente admisibles ${ }^{40}$.

Con todo, hasta finales de 1967 el Tribunal Supremo no admitió definitivamente la interpretación de la Cuarta Enmienda defendida por Brandeis en Olmstead v. The United States. Charles Katz fue detenido por las autoridades federales en Los Ángeles tras el registro de las conversaciones de sus actividades ilegales por un mecanismo de escucha electrónico acoplado al exterior de una cabina de teléfono. Abandonando su enfoque de la invasión material, el Tribunal afirmó en Katz v. United States que el espionaje electrónico constituye «registro» en el sentido de la Cuarta Enmienda, cuyo propósito es proteger a las personas y no simplemente los lugares, amparando constitucionalmente la privacidad en el marco de la Cuarta Enmienda ${ }^{41}$. Basándose en la opinión mayoritaria del Tribunal, el Juez Harlan ofreció en su voto concurrente la noción de «expectativa razonable de privacidad», según la cual sólo existe una zona de privacidad garantizada por la Cuarta Enmienda si la persona ha actuado conforme a una real expectativa de privacidad

38 «stamos entrando rápidamente en una época en que no existe privacidad, donde todo el mundo está expuesto a vigilancia todo el tiempo; donde no hay secretos para el Gobierno. Se incrementan en proporciones geométricas las infracciones violentas de la privacidad por el Gobierno. Escuchas telefónicas y grabaciones ocultas (bugging) se pasean rampantes, sin tutela judicial efectiva o control legislativo. Es usual encontrar cabinas secretas de observación en las oficinas del Gobierno, y televisión de circuito cerrado en la industria, y hasta en los baños $[\ldots .$.$] Estos y otros muchos ejemplos demuestran una alarmante tendencia a aniquilar gradualmente la pri-$ vacidad y dignidad de nuestros ciudadanos mediante pasos casi imperceptibles. Cada una de estas acciones tomadas individualmente puede que no tengan ninguna importancia, pero cuando se toman en su totalidad, vemos cómo está empezando a surgir una sociedad muy distinta a cualquiera que hayamos visto — una sociedad en la que el gobierno podrá inmiscuirse en las regiones más secretas de la vida de la persona a voluntad», Osborn v. United States, 385 U.S. 323, 341-343 (1966) (Douglas, J., dissenting).

39387 U.S. $523,528(1967)$.

40388 U.S. 41 (1967).

41 «Porque la Cuarta Enmienda protege a las personas, no los lugares. Lo que una persona conscientemente expone al público, incluso en su propia casa y oficina, no es un asunto de protección de la Cuarta Enmienda. Pero lo que trata de preservar como privado, incluso en una zona accesible al público, puede ser protegido constitucionalmente», Katz v. United States, 389 U.S. 347, 351 (1967). 
y si tal expectativa la sociedad está preparada para reconocerla como «razonable» ${ }^{42}$. Estándar adoptado inmediatamente por la mayoría del Tribunal Supremo en Terry v. Obio, al afirmar que la prohibición de registro arbitrario establecido en la Cuarta Enmienda y la expectativa razonable de privacidad no se viola cuando un oficial de policía detiene a un sospechoso en la calle y realiza un registro de su persona si tiene una sospecha razonable, basada en hechos específicos, de que ha cometido o va a cometer un crimen, está armado y es peligroso ${ }^{43}$.

Desde entonces, en la extensa jurisprudencia del Alto Tribunal se ha reconocido una expectativa razonable de privacidad en diversos ámbitos y con distintas gradaciones, así respecto del la utilización de mecanismos de interceptación y grabación ${ }^{44}$, en los supuestos de registros administrativos de casas y oficinas ${ }^{45}$, en los registros de equipajes y taquillas ${ }^{46}$, así como en los supuestos de inspección de licencia de circulación y registro de vehículos en los controles policiales de tráfico ${ }^{47}$. En sentido contrario, no se ha reconocido una expectativa razonable de privacidad garantizada por la Cuarta Enmienda en los diversos supuestos de acciones policiales dirigidas a la prevención y detección de actividades criminales, así, en relación con los datos bancarios individuales ${ }^{48}$, y en los registros y acciones policiales relacionados con la lucha contra el narcotráfico ${ }^{49}$, considerándose que en estos supuestos prevalece el interés general en la persecución y prevención de tales actividades delictivas frente a una determinada expectativa de privacidad individual. Sin embargo, en 2001 el Tribunal Supremo sostuvo en Kyllo $v$. United States que la utilización de un escáner localizado en un lugar público que capta imágenes térmicas del interior de una vivienda para vigilar la radiación de calor del domicilio de una persona sospechosa de cultivar marihuana constituye un «registro» en el sentido de la Cuarta Enmienda, afirmando que en la «santidad del hogar» cualquier aspecto reservado de la persona está incluido en la esfera de su privacidad ${ }^{50}$. Por tanto, desde Katz $v$. United States se ha generado una extensa y vacilante jurisprudencia, que supedita el concepto de «expectativa razonable de privacidad» a las cambiantes mayorías del Tribunal, que pueden ampliar o restringir su alcance hasta vaciarlo de con-

42389 U.S. 347, 361 (1967) (Harlan, J., concurring).

43392 U.S. 1, 9 (1968). Vid. también, Rakas v. Illinois, 439 U.S. 128 (1978); Smith v. Maryland, 442 U.S. 735 (1979); United States v. Salvucci, 448 U.S. 83 (1980); Rawlings v. Kentucky, 448 U.S. 98 (1980); Michigan v. Long, 463 U.S. 1032 (1983); y Hiibel v. Sixth Judicial District Court of Nevada, 542 U.S. 177 (2004).

44 Entre otros, vid. Berger v. New York, 388 U.S. 41 (1967); United States v. United States Dist. Court, 407 U.S. 297 (1972).

45 Vid. Camara v. Municipal Court, 387 U.S. 523 (1967); Mancusi v. De Forte, 392 U.S. 364 (1968); G.M. Leasing Corp. v. United States, 429 U.S. 338 (1977); Donovan v. Dewey, 452 U.S. 594 (1981); New York. v. Burger, 482 U.S. 691 (1987).

46 Vid. United States v. Chadwick, 433 U.S. 1 (1977); Arkansas v. Sanders, 442 U.S. 753 (1979); United States v. Karo, 468 U.S. 705 (1984).

47 Vid. especialmente Delawere v. Prouse, 440 U.S. 648 (1979).

48 United States v. Miller, 425 U.S. 435 (1976).

49 De la abundante jurisprudencia, vid. United States v. Place, 462 U.S. 696 (1983); California v. Greengood, 486 U.S. 35 (1988); New Jersey v. T.L.0.,469 U.S. 325 (1985); Oliver v. United States, 466 U.S. 170 (1984); California v. Ciraolo, 476 U.S. 207 (1986); Dow Chem. Co. v. United States, 476 U.S. 277 (1986); United States v. Dunn, 480 U.S. 294 (1987); Florida v. Riley, 488 U.S. 445 (1989); Skinner v. Railway Labor Executives' Ass'ns, 489 U.S. 602 (1989); National Treasury Employees Union v. Von Raab, 489 U.S. 656 (1989).

50533 U.S. 27 (2001). 
tenido. De ahí la generalizada crítica de la mayoría de la doctrina norteamericana, que viene denunciando la progresiva reducción del ámbito de protección de la Cuarta Enmienda ${ }^{51}$.

Con todo, aunque durante más de la mitad del siglo XX el Tribunal Supremo ha venido señalado expresamente como intereses protegidos por la Cuarta Enmienda la libertad individual, la integridad personal, la inviolabilidad de la persona, la santidad de la persona, e, incluso, el derecho a la libertad de movimientos, sin embargo, desde Katz v. United States el interés central de la Cuarta Enmienda ha sido la protección de la privacidad individual, de aquellos ámbitos de la esfera privada que tienden a preservar esos intereses de «secreto», «santuario» o «soledad» individual frente a la ilegítima intromisión estatal, que han fundamentado su protección constitucional y que están implícitos en la centenaria formulación del derecho a la privacidad como «the right to be let alone» ${ }^{52}$. Formulación asimismo presente en la interpretación del concepto de libertad de la Decimocuarta Enmienda que igualmente ha hecho posible la «inducción» en el sistema constitucional norteamericano de un «fundamental right to privacy».

\section{LA INDUCCIÓN CONSTITUCIONAL DEL DERECHO FUNDAMENTAL A LA PRIVACIDAD: LA «LIBERTAD SUSTANTIVA» DE LA DECIMOCUARTA ENMIENDA}

La década de los sesenta supuso un giro importante en la jurisprudencia norteamericana relativa a la privacidad. Hasta ese momento, el reconocimiento constitucional del derecho a la privacidad había girado en torno a la prohibición de la Cuarta Enmienda de registros arbitrarios personales y domiciliarios. Sin embargo, a mediados de 1960 se produce un cambio importante en la jurisprudencia del Tribunal Supremo, al reconocer un derecho fundamental a la privacidad en la toma de decisiones de especial relevancia para el desenvolvimiento de la personalidad individual, implícito en el «concepto de libertad» que desde finales del siglo XIX el Tribunal Supremo ha interpretado ampara la cláusula del debido proceso (due process of law) de la Decimocuarta Enmienda, que prohíbe que una ley estatal prive a una persona de su vida, libertad o propiedad arbitrariamente y que ha sido conocida como la Lochner Era ${ }^{53}$. Así, como se analiza a continuación, a lo lar-

51 De la diversa doctrina que cuestiona la vacilante aplicación del test de expectativa razonable de privacidad, vid. KLANCY, Th. K., «What Does the Fourth Amendment Protect: Property, Privacy or Security», Wake Forest Law Review, vol. 33, 2009, págs. 307-370, especialmente págs. 340-344; CLOud, M., «The Fourth Amendment During the Lochner Era: Privacy, Property and Liberty in Constitutional Theory», Stanford Law Review, vol. 48, 1996, págs. 555-631, especialmente pág. 567; SundBY, S. E., «Everyman’s» Fourth Amendment: Privacy or Mutual Trust Between Government and Citizen?», Columbia Law Review, vol. 94, 1994, págs. 1751-1812, especialmente págs. 1758-71.

52 En este sentido, vid. Gormley, K., «One Hundred Years of Privacy», op. cit., pág. 1374.

53 Vid. Allgeyer v. Louisiana, 165 U.S. 578 (1897). Esta concepción del «debido proceso sustantivo» se confirma en el caso Lochner v. New York, en el que el Tribunal declara inconstitucional una ley neoyorkina que reducía el horario laboral de los trabajadores de panaderías, alegando que se vulneraba la libertad contractual de forma arbitraria, incompatible con la cláusula del debido proceso de la Decimocuarta Enmienda. Se iniciaría así una línea jurisprudencial conocida como la Era Lochner que terminaría con el caso West Coast Hotel Co. v. Parrish, 300 U.S. 379 (1937). De la extensa bibliografía, vid. Berstein, D. E., Rehabilitating Lochner: Defending Indi- 
go de una extensa y vacilante jurisprudencia, el Tribunal Supremo ha ido estableciendo que la libertad consagrada por la cláusula del debido proceso de la Decimocuarta Enmienda incluye el derecho a casarse, a tener hijos y a decidir sobre su educación y la crianza de éstos, el derecho a la privacidad marital y al uso de anticonceptivos, el derecho al aborto y el derecho a la orientación sexual y a las prácticas homosexuales consentidas entre adultos en el ámbito privado, habiéndose planteado incluso si el derecho fundamental a la privacidad amparado por la cláusula del debido proceso de la Decimocuarta Enmienda incluye el derecho a rechazar un determinado tratamiento médico y a decidir sobre la propia muerte.

Ya en la década de los veinte esta interpretación había permitido al Tribunal deducir de la esfera de protección de la Decimocuarta Enmienda el derecho de los padres a educar a los hijos en los centros escolares de su elección (Pierce v. Society of Sisters) ${ }^{54}$. Igualmente, en Meyer $v$. Nebraska reconoció el derecho a recibir educación en lengua extranjera, afirmando el juez McReynolds en nombre de la mayoría del Tribunal que la Decimocuarta Enmienda protege «no sólo la ausencia de restricciones corporales, sino también el derecho del individuo a celebrar contratos, dedicarse a cualquier ocupación común, casarse, formar un hogar y educar a sus hijos, adorar a Dios según los dictados de su conciencia y, en general, a gozar de esos privilegios que el common law ha reconocido durante largo tiempo esenciales para la búsqueda ordenada de la felicidad de los hombres libres» ${ }^{55}$. Cuarenta años más tarde, el Tribunal Supremo «indujo» expresamente el derecho fundamental a la privacidad de la «dimensión sustantiva» de la cláusula del debido proceso (substantive due process) de la Decimocuarta Enmienda, al declarar inherente al concepto de libertad de la mencionada cláusula el derecho a la toma de decisiones en el ámbito privado sin injerencias estatales, otorgándole una "posición preferente» que impone a toda legislación estatal que pretenda su restricción demostrar una extraordinaria justificación, esto es, un interés estatal relevante (compeling state interest).

En 1961, el juez Harlan defendió en su voto particular discrepante en Poev. Ullman que la ley de control de la natalidad del Estado de Connecticut de 1879 violaba la Decimocuarta Enmienda, afirmando que penalizar la utilización de métodos anticonceptivos por personas casadas constituye una intolerable e injustificada invasión en uno los aspectos más reservados de la vida privada del individuo ${ }^{56}$. Cuatro años más tarde, en 1965, el Tribunal Supremo declaró por primera vez en Griswold v. Connecticut la inconstitucionalidad de una norma estatal que prohibía la venta y utilización de anticonceptivos por considerarla lesiva del «derecho fundamental a la privacidad». Realmente, la opinión mayoritaria del Tribu-

vidual Rights Against Progressive Reform, University of Chicago Press, Chicago, 2011; del mismo autor, «Lochner v. New York: A Centennial Retrospective», Washington University Law Quarterly, vol. 85, núm. 5, 2005, págs. 1469-1528; y también de BERSTEIN, «Lochner Era Revisionism, Revised: Lochner and the Origins of Fundamental Rights Constitutionalism», Georgetown Law Journal, vol. 92, 2003, págs. 1-60.

54268 U.S. 510 (1925).

55262 U.S. $390,399(1923)$.

56367 U.S. 497, 539 (1961) (Harlan, J., dissenting). En la misma línea de la opinión discrepante del juez Harlan, defendiendo un derecho a la privacidad en base a la Novena Enmienda, vid. ReDLICH, N., «Are there 'certain rights retained by the people'», New York University Law Review, vol. 37, 1962, págs. 788 y ss.; WATson, G., «The Ninth Amendment: Source of a Substantive Right to Privacy», John Marshall Law Review, vol. 19, 1985-1986, págs. 959-981. 
nal, formulada por el juez Douglas, derivó la protección de la privacidad de las llamadas «zonas de penumbra» emanadas por específicas garantías reconocidas en el Bill of Rights, que le otorgan a las mencionadas garantías vitalidad y real existencia. Entre las específicas garantías de las que se derivan zonas de privacidad, Douglas señaló expresamente el derecho de asociación incardinado en la Primera Enmienda, la prohibición de la Tercera Enmienda de requisar domicilios particulares por los soldados sin el consentimiento de su propietario en tiempos de paz, la garantía de la Cuarta Enmienda frente a registros y requisas arbitrarias de personas y domicilios, la garantía de la Quinta Enmienda de no incriminación contra uno mismo, concluyendo el Tribunal que bajo este conjunto de derechos subyace un derecho general a la privacidad amparado por la Novena Enmienda ${ }^{57}$. Asimismo, el juez Goldberg afirma en su voto concurrente que el concepto de libertad protege ciertos derechos fundamentales más allá de los expresamente formulados por la Declaración de Derechos, fundamentando el derecho a la privacidad en base a la Novena Enmienda ${ }^{58}$. Y los jueces Harlan y White acuden expresamente en su voto concurrente a la cláusula del debido proceso legal como parámetro constitucional de interpretación, afirmando que la ley de Connecticut violaba intereses constitucionales implícitos en el concepto «of ordered liberty». ${ }^{59}$

En 1967, el caso Loving v. Georgia permitió al Tribunal Supremo declarar inconstitucional por violación de la Decimocuarta Enmienda la legislación estatal de Virginia que prohibía y castigaba los matrimonios interraciales exclusivamente sobre la base de la clasificación racial, afirmando que la restricción del derecho personal a contraer matrimonio en base a la clasificación racial no sólo viola el significado central de la cláusula de

57 «Existen en la declaración de derechos específicas garantías que tienen zonas de penumbra formadas por emanaciones de aquellas garantías que contribuyen a darles vida y sustancia [...] Varias garantías crean zonas de privacidad. El derecho de asociación es, como hemos visto, uno de los que está contenido en la penumbra de la Primera Enmienda. La Tercera Enmienda, en su prohibición contra el alojamiento de soldados en cualquier casa en tiempos de paz sin el consentimiento de su propietario, es otra faceta de tal privacidad. La Cuarta Enmienda afirma explícitamente el derecho del pueblo a estar a salvo de allanamientos y de secuestros irrazonables en sus personas, casas, papeles y pertenencias. La Quinta Enmienda, en la cláusula contra la autoincriminación, permite al ciudadano crear una zona de privacidad que el gobierno no puede obligarle a renunciar en su perjuicio. La Novena Enmienda establece que la enumeración en la Constitución de determinados derechos no será entendida como denegación o disminución de otros retenidos por el pueblo [.... La Cuarta y Quinta Enmiendas fueron descriptas en Boyd $v$. United States como una protección contra toda invasión gubernamental de la santidad de la morada de cada persona y de las privacidades de la vida. Recientemente nos referimos en Mapp $v$. Obio a la Cuarta Enmienda como creadora de un derecho de privacidad no menos importante que cualquiera de los otros derechos cuidadosa y particularmente reservados al pueblo [...] Estos casos dan testimonio de que es legítimo el derecho de privacidad cuyo reconocimiento se reclama en el caso», Griswold v. Connecticut, 381 U.S. 479, 484-485 (1965).

58381 U.S. 479, 485-498 (1965) (Goldberg, A. J., concurring).

59381 U.S. 479, 500 (1965). Sobre este caso, vid. JoHnson, J. W., Griswold v. Connecticut: Birth Control and the Constitutional Right of Privacy, University Press of Kansas, Lawrence, 2005; TusHnEt, M., «Two Notes on the Jurisprudence of Privacy», Constitutional Commentary, vol. 8, 1991, págs. 75 y ss.; GreELY, H., «A Footnote to 'Penumbra' in Griswold v. Connecticut», Constitutional Commentary, vol. 6, 1989, págs. 262 y ss., especialmente págs. 262-265; Henkin, L., «Privacy and Autonomy», Columbia Law Review, vol. 74, 1974, págs. 1410-1433, especialmente págs. 1421-1422; Dixon, R. G., The Right of Privacy: A Symposium on the Implications of Griswold v. Connecticut, 381 U.S. 497 (1965), New York, Da Capo Press, 1971. 
igual protección de la Decimocuarta Enmienda sino también el derecho de todos los ciudadanos de los Estados a no ser privados de la libertad sin el debido proceso legal ${ }^{60}$.

Cinco años más tarde, en 1972, un asunto similar al caso Griswold es tomado en consideración por el Tribunal Supremo, aunque en este caso el Tribunal abandona la concepción sustantiva de la privacidad al amparar la distribución de material anticonceptivo a personas sin vínculo matrimonial en base a la cláusula de igual protección ante la ley (equal protection clause) de la Decimocuarta Enmienda, afirmando en Eisenstadt v. Baird que la ley estatal de Massachusetts que prohibía tal distribución de contraceptivos con la pretensión de satisfacer un interés estatal en evitar relaciones sexuales extramatrimoniales violaba el derecho de las personas solteras a la equal protection clause de la Decimocuarta Enmienda, declarando que si el derecho a la privacidad significa algo es, sin duda, el derecho de toda persona, casada o soltera, a permanecer libre de cualquier intrusión estatal injustificada respecto de asuntos tan fundamentales como la decisión de dar a luz o concebir un hijo ${ }^{61}$.

Se reconoce así un «derecho a la autonomía reproductiva» que se confirmaría cinco años más tarde en Carey v. Population Services International, al invalidar el Tribunal Supremo una ley estatal de Nueva York que sólo permitía la venta de medios contraceptivos a personas mayores de dieciséis años, prohibiendo expresamente su venta a menores de esa edad. Expresando la opinión del Tribunal, el juez Brennan afirma que una decisión tan fundamental como la de tener un hijo sólo puede ser restringida por la legislación estatal en base a un interés esencial (compelling interest), y ninguno de los intereses generales aducidos por el Estado de Nueva York, tales como la protección de la salud o el reforzamiento de otras leyes, es considerado por el Tribunal Supremo esencial frente al interés privado a la autonomía reproductiva, señalando que desde Griswold «la Constitución protege la decisión de la persona de tener un hijo frente a cualquier intromisión injustificada por el Estado» ${ }^{62}$.

Y sobre el argumento de Griswold descansaría en 1973 uno de los pronunciamientos más importantes del Tribunal Supremo sobre la protección constitucional de la privacidad. En efecto, en el célebre caso de Roe $v$ Wade el Tribunal incluyó en el ámbito del derecho fundamental a la privacidad la decisión personal de la mujer de practicarse un aborto en las doce primeras semanas de gestación ${ }^{63}$. Las leyes del Estado de Texas tipificaban como delito la interrupción del embarazo, exceptuándose los supuestos de prescripción médica para salvar la vida de la madre. La legislación de Texas era similar a la vigente en la mayoría de los Estados norteamericanos desde finales del siglo XIX, justificada, entre otras razones, por el interés estatal en la protección de la vida prenatal al considerarse que la vida humana merece protección desde el momento mismo de la concepción. Una ciudadana de Texas soltera y embarazada, Jane Roe, recurrió la consti-

60388 U.S. 1, 11 (1967).

61405 U.S. 438, 455 (1972). La doctrina norteamericana ha sido muy crítica con la doble racionalidad constitucional aplicada por el Tribunal Supremo a dos casos tan similares como Griswold e Eisesntadt, al respecto vid. Gerety, T., «Doing Without Privacy», Ohio State Law Journal, vol. 42, 1981, págs. 143-144; WeLlinGTON, H., «Common Law Rules and Constitutional Double Standards», Yale Law Journal, vol. 83, 1973, págs. 221 y ss., especialmente pág. 296.

62431 U.S. 678, 687 (1977).

63410 U.S. 113 (1973). 
tucionalidad de las leyes estatales que le habían impedido practicarse legalmente un aborto porque la continuación del embarazo no ponía en peligro su vida ${ }^{64}$.

Expresando la opinión mayoritaria del Tribunal Supremo, el juez Blackmun afirma que aunque la Constitución norteamericana no menciona expresamente un derecho a la privacidad, sin embargo, el Tribunal había reconocido previamente que el derecho a la privacidad o a la garantía de ciertos ámbitos o zonas de privacidad se amparaban en la Constitución. Así, tanto el Tribunal como algunos de sus magistrados habían residenciado la fundamentación de tal derecho en la Primera Enmienda (Stanley v. Georgia) ${ }^{65}$, en la Cuarta y Quinta Enmiendas, en las llamadas «zonas de penumbra» del Bill of Rights (Griswold v. Connecticut) ${ }^{66}$, en la Novena Enmienda (voto concurrente del juez Goldberg en Griswold v. Connecticut) o en el concepto de libertad garantizado por la Primera Sección de la Decimocuarta Enmienda (Meyer v. Nebraska ${ }^{67}$. Tales pronunciamientos judiciales argumenta Blackmun - establecen que los derechos personales que pueden considerarse «fundamentales» o implícitos en el concepto de libertad están incluidos en la garantía de la privacidad personal. Más aún, reiterada jurisprudencia del Tribunal igualmente había afirmado que el derecho a la privacidad se extendía a aspectos relacionados con el matrimonio (Loving v. Virginia) $)^{68}$, la procreación (Skinner v. Oklaboma) ${ }^{69}$, la contracepción (Eisenstadt v. Baird) ${ }^{70}$ y la crianza y educación de los hijos (Pierce v. Society of Sisters) ${ }^{71}$. Atendiendo a todas estas consideraciones y al probable detrimento personal, tanto físico como psicológico, que la legislación estatal causaría a la mujer embarazada de negársele tal elección, afirma Blackmun que, bien sea en base al concepto de libertad de la Decimocuarta Enmienda, bien en base a la Novena Enmienda, el derecho a la privacidad es suficientemente amplio como para incluir la decisión de la mujer de continuar su embarazo $^{72}$.

Sin embargo, el Tribunal Supremo no otorga un derecho absoluto a la mujer embarazada, antes al contrario, al mismo tiempo que reconoce esa esfera privada digna de protección, afirma igualmente la conveniencia de una regulación estatal sobre determinadas áreas al objeto de proteger intereses relevantes como la protección de la salud de la mujer, el mantenimiento de los estándares médicos así como la protección de la «vida en potencia». Como afirma el Tribunal, la mujer embarazada no puede ser aislada en su privacidad en la medida en que es portadora de un embrión y, avanzada la gestación, de un feto. De ahí que el Estado pueda tener un legítimo interés tanto en proteger a la mujer embarazada como en proteger la potencialidad de la vida humana. Sin embargo, el Tribunal considera que mientras que la salud de la mujer prevalece durante el primer tri-

64 Sobre quién era realmente Jane Roe así como sobre las circunstancias que motivaron su reclamación judicial, vid. Tribe, L. H., Abortion: The Clash of Absolutes, Norton, New York, 1990, pág. 5; FrienLY, F. y MARTHA, J. H., The Constitution: That Delicate Balance, McGraw-Hill, New York, 1993, págs. 202-204.

65394 U.S. 557 (1969).

66381 U.S. $479(1965)$

67262 U.S. $390(1923)$

68388 U.S. 1 (1967).

69316 U.S. 535 (1942).

70405 U.S. 438 (1972).

71268 U.S. 510 (1925).

72 Roev. Wade, 410 U.S. 113, 153 (1973). 
mestre de gestación, el interés relevante en la vida potencial prevalece cuando ésta ha alcanzado «viabilidad», de ahí que la regulación estatal que proteja la vida fetal que es viable alcance lógica y biológica justificación ${ }^{73}$.

En su voto particular concurrente, el juez Stewart coincide con la mayoría del Tribunal, afirmando igualmente que los derechos específicos de elección personal en ámbitos del matrimonio y de la vida familiar están amparados por el «concepto de libertad» protegido por la cláusula del debido proceso legal de la Decimocuarta Enmienda, incluyéndose entre estos derechos el derecho de la mujer a decidir si continua con su embarazo, de ahí que el interés estatal esgrimido para justificar la restricción del derecho deba pasar el escrutinio reforzado que requiere la Decimocuarta Enmienda ${ }^{74}$. Igualmente, el juez Douglas afirma en su voto concurrente que el derecho a la privacidad es anterior al Bill of Rights, señalando tres niveles de derechos fundamentales derivados de la privacidad: en primer lugar, el derecho al control automático sobre la inteligencia y la personalidad; en segundo término, la libertad de elección sobre las cuestiones básicas de la propia vida, como el matrimonio, la procreación y la educación de los hijos; y el tercer nivel, representado por la libre elección de los medios para cuidar la persona y la salud ${ }^{75}$.

El juez Rehnquist, sin embargo, disiente de la opinión mayoritaria y niega que el derecho a la privacidad esté en juego en el caso Roe $v$. Wade, considerando que la mayoría del Tribunal no había respetado el procedimiento exigido jurisprudencialmente en los casos en los que se aplican los estándares del debido proceso sustantivo (substantive due process), que obligan a examinar la finalidad de las políticas legislativas para determinar si el interés estatal es esencial, esto es, si está presente un «compelling interest». Rehnquist critica igualmente la decisión mayoritaria del Tribunal de dividir el período de gestación en tres diferentes estadios, definiendo las restricciones permisibles que la legislación estatal puede imponer en cada uno. Delimitación que se aproxima más al ámbito de la «judicial legislation» que — argumenta Rehnquist— a la interpretación del contenido constitucional de la Decimocuarta Enmienda ${ }^{76}$.

Como puede imaginarse, uno de los debates constitucionales más importantes que ha generado el caso Roe v. Wade es el parámetro de interpretación constitucional que permitió el reconocimiento del derecho fundamental a abortar durante el primer trimestre de gestación. Como es sabido, en la doctrina norteamericana viene distinguiéndose entre la corriente defensora de una interpretación constitucional respetuosa del «texto» de la Constitución - lo que se conoce como «interpretativismo» (interpretativism) u «originalismo» (orignalism) — , esto es, la interpretación constitucional debe basarse exclusiva-

73 El Tribunal Supremo considera que el feto es viable en el momento en que es potencialmente capaz de vivir fuera del claustro materno aunque sea con ayuda artificial, vid. Roe v. Wade, 410 U.S. 113, 160 (1973). Sin embargo, en Planned Parenthood of Central Missouri v. Danforth, 428 U.S. 52 (1976), se admitió la constitucionalidad de la legislación abortiva de Missouri que definía la viabilidad del feto en términos vagos e imprecisos, afirmando el Tribunal Supremo que, al igual que había reconocido en Roe v. Wade, la viabilidad del feto era en todo caso un asunto reservado al juicio médico y dependiente de los avances técnicos, de ahí la flexibilidad del término, considerando que no es función del legislador ni de los jueves identificar el momento de la «viabilidad», dado que se trata esencialmente de un concepto médico que sólo puede concretarse en cada caso concreto, al respecto, vid. Colautti v. Franklin, 439 U.S. 379 (1979).

74 Roe v. Wade, 410 U.S. 113, 169 (1973).

75 Ibídem, pág. 209.

76 Ibídem, págs. 172-174. 
mente en normas establecidas claramente en la Constitución escrita, y la corriente que defiende la validez de una interpretación constitucional más allá del propio texto constitucional — «no-interpretativismo» (noninterpretativism o nonoriginalism) ${ }^{77}$. Así, mientras que para los defensores de una interpretación constitucional «originalista» el Caso Roe no es Derecho constitucional ${ }^{78}$, para otros, por el contrario, la decisión mayoritaria de Roe $v$. Wade aplica acertadamente criterios de interpretación constitucional, permitiendo reconocer derechos fundamentales difícilmente deducibles de una interpretación textual o literal de la Constitución norteamericana ${ }^{79}$.

En efecto, la línea de argumentación de los casos Meyer-Pierce-Skinner-GriswoldEissestadt-Roe delimita una esfera de intereses bajo el término de «privacy» implícitos en el concepto de libertad de la Decimocuarta Enmienda. En el núcleo de esta esfera de intereses está el derecho de la persona a tomar por sí misma las decisiones «fundamentales» que configuran su vida personal y familiar ${ }^{80}$. Sin embargo, la cuestión problemática ha sido delimitar en qué consiste la «fundamentalidad» de esos aspectos de la vida personal que constituyen una zona de autonomía digna de protección por el derecho a la privacidad. Así, en 1986, en el caso Thornburgh v. American Collage of Obstretician and Ginecologists, que invalidó algunas restricciones abortivas de la legislación estatal de Pennsylvania, el voto discrepante del juez White, a la que se adhirió el juez Rehnquist, atacaba muy directamente la principal premisa de Roe $v$. Wade, cuestionando, entre otros aspectos, la «fundamentalidad» del derecho de la mujer a terminar el embarazo, considerándose que tal elección no puede inferirse implícita en el concepto de la libertad enraizado en la historia y la tradición de la nación norteamericana ${ }^{81}$.

La opinión de White alcanzará a la mayoría del Tribunal Supremo en 1989, en el caso Webster v. Reproductive Health Services, que declaró la constitucionalidad de la legislación de Missouri que imponía la aplicación de terminados tests cuando el embarazo había alcanzado las veinte semanas de gestación, afirmando que el rígido criterio de Roe

77 Vid. Linzer, P., «The Carolene Products Footnote and the Preferred Position of Individual Rights: Louis Lusky and John Hart Ely vs. Harlan Fiske Stone», Constitutional Commentary, vol. 12, 1995; BENNET, R., «Objectivity in Constitutional Law», University of Pennsylvania Law Review, vol. 132, 1984, pág. 446 y nota 3; FALlon, R., «A Constructivist Coherence Theory of Constitutional Interpretation», Harvard Law Review, vol. 100, 1987, págs. 1211-1217; Grey, T., «The Constitution as Scripture», Stanford Law Review, vol. 37, 1984, pág. 1; y también de GREY «Do We Have an Unwritten Constitution?», Stanford Law Review, vol. 27, 1975, pág. 703 .

78 Cfr. ElY, J., «The Wages of Crying Wolf: A Comment on Roe v. Wade», Yale Law Journal, vol. 82, 1973, págs. 935-37, 947-949; Bork, R. H., The Tempting of America: The Political Seduction of The Law, Free Press, New York, 1990, págs. 111-116. En esta línea, vid. también, Posner, R., «The Uncertain Protection of Privacy in the Supreme Court», Supreme Court Review, 1979, págs. 173 y ss., especialmente, págs. 199-200.

79 Entre otros, vid. Tribe, L., Abortion: The Clash of Absolutes, op. cit., pág. 99; LuPIN, I., «Constitucional Theory and the Search for the Workable Premise», Dayton Law Review, vol. 8, 1983, pág. 583; GranO, J., "Judicial Review and a Written Constitution in a Democratic Society», Wayne Law Review, vol. 28, 1981, pág. 59. Vid. también la interesante argumentación de DwORKING, R., «Unenumerated Rights», University of Chicago Law Review, vol. 59, 1992, págs. 381 y ss., especialmente págs. 387-388.

80 En este sentido, vid. Heymann, P. \& Barzelay, D., «The Forest and the Trees: Roe v. Wade and Its Critics», Boston University Law Review, vol. 53, 1973, págs. 765 y ss., especialmente pág. 772. En sentido contrario, argumentando que el interés en la toma de decisiones relativa a la vida personal y familiar no puede equiparse al relevante interés estatal en los supuestos de aborto, vid. REGAN, D., «Rewriting Roe v. Wade», Michigan Law Review, vol. 77, 1979, págs. 1569 y ss., especialmente pág. 1639.

81476 U.S. 747,792 (1986). 
v. Wade sobre la viabilidad del feto así como la diferenciación entre los tres estadios del embarazo había demostrado ser «irracional en lo principal e inviable en la práctica» ${ }^{82}$. Sin embargo, como se señala en el voto discrepante del juez Blackmun, al que se adhieren Brennan y Marshall, la decisión mayoritaria en Webster desconoce completamente el irreducible mínimo de Roe v. Wade, esto es, el reconocimiento en el ámbito del derecho a la privacidad relativo a la toma de decisiones personales autónomas de un derecho constitucional fundamental de la mujer a decidir si continua su embarazo ${ }^{83}$. Sin duda, la racionalidad o «fundamentalidad» que subyace en el caso Roe v. Wade es que pocas decisiones son tan básicas para la autonomía y dignidad individual, y, por tanto, más relativas a la esfera privada de la libertad individual, que la única, personal e íntima decisión de la mujer de continuar con el embarazo ${ }^{84}$.

Y no menos importante que la protección de la inderogable autonomía individual de la mujer es el respeto a su igualdad sexual, porque el derecho de la mujer al control reproductivo es también un derecho de su igualdad sexual, de ahí que la legislación criminal abortiva del tipo que se invalidó en el Caso Roe violase también la igual protección de la ley amparada por la equal protection clause de la Decimocuarta Enmienda ${ }^{85}$. Así, al expresar la opinión mayoritaria del Tribunal Supremo en Planned Parenthood of Southeastern Pennsylvania v. Casey —en el que se confirmó el principal argumento del Caso Roe—, los Jueces O’Connor, Kennedy y Saute reconocieron la estrecha conexión entre la capacidad de la mujer para controlar su vida reproductiva y su igual participación en la vida económica y social. En efecto, en 1992 el Tribunal Supremo ofreció en Planned Parenthood of Southeastern Pennsylvania v. Casey su más elaborada interpretación del ámbito de la privacidad protegido por el «fundamental right to privacy», conceptualizando la privacidad como el derecho a la no injerencia estatal sobre aquellas decisiones que son importantes para el desarrollo de la propia personalidad ${ }^{86}$. El caso cuestionaba la constitucionalidad de

82492 U.S. 490, 494 (1989).

83 Ibídem, pág. 537.

84 En este sentido, vid. Estrich, S. y Sullivan, K., «Abortion Politics: Writing for an Audience of One», University of Pennsylvania Law Review, vol. 138, 1989, págs. 125-127.

85 «Debido a que la organización social de la reproducción es un importante baluarte de la desigualdad social de la mujer, cualquier interpretación constitucional del principio de la igualdad entre los sexos debe prohibir leyes, políticas estatales o prácticas y actos oficiales que privan a la mujer del control reproductivo o castigan a las mujeres por su papel en la reproducción [...] El derecho de la mujer al control reproductivo es un derecho de la igualdad sexual, porque es incompatible con un mandato de igualdad para el estado, establecido por ley, colaborar con la desigualdad social sobre la base del sexo... Bajo este análisis de la igualdad sexual, las leyes que criminalizan el aborto del tipo invalidadas en el Caso Roe violan la igual protección de las leyes», Mackinnon, C., «Reflections on Sex Equality Under Law», Yale Law Journal, vol. 100, 1991, págs. 1281 y ss., especialmente pág. 1319. En esta línea argumental, entre otros, vid. SunsteIn, C., The Partial Constitution, Harvard University Press, Cambridge, Mass., 1993, págs. 272-285; SIEGel, R., «Reasoning from the Body: A Historical Perspective on Abortion Regulation and Questions of Equal Protection», Stanford Law Review, vol. 44, 1992, págs. 350-380; STRAUSs, D., «Abortion, Toleration and Moral Uncertainty», Supreme Court Review, 1992, págs. 18-22.

86 «Estas cuestiones, concernientes a las opciones más íntimas y personales que una persona puede hacer en su vida, opciones esenciales para la autonomía y dignidad personal, son centrales a la libertad protegida por la Decimocuarta Enmienda. En el corazón de la libertad está el derecho de cada uno a definir el concepto propio de la existencia, el significado del universo y el misterio de la vida humana. Las creencias acerca de estos asuntos no pueden definir los atributos de la personalidad si se formaron bajo la coacción del Estado», Planned Parenthood of Southeastern Pa.v. Casey, 505 U.S. 833, 851 (1992). 
cinco previsiones legislativas de la Abortion Control Act de 1982 de Pennsylvania. Entre otras exigencias, la ley estatal requería el consentimiento informado de la mujer embarazada antes de la realización del aborto, exigiendo igualmente que la mujer fuese provista de cierta información al menos veinticuatro horas antes de practicársele el aborto. En el supuesto de menores, la legislación de Pennsylvania requería el consentimiento informado de los padres, permitiendo el recurso a la autorización judicial si la menor no podía obtenerlo. Y otra previsión legislativa obligaba a la mujer casada a firmar una declaración que indicase que había comunicado a su marido su intención de abortar. Consciente de la vacilante jurisprudencia que reflejaban las decisiones de Thornburgh y Webster, el Tribunal Supremo concluye tras un extenso razonamiento que el principal argumento de Roe v. Wade se confirma en sus aspectos fundamentales, reconociendo expresamente el derecho de la mujer a elegir libremente tener un aborto durante el primer trimestre de gestación y a obtenerlo sin sufrir ningún tipo de injerencia injustificada por parte del Estado, afirmando que la protección constitucional deriva de la dimensión sustantiva que desde hacía más de un siglo se había reconocido al concepto de libertad amparado por la garantía del debido proceso legal de la Decimocuarta Enmienda. Con todo, el Tribunal restringe el ámbito de protección amparado en Roe $v$. Wade, al permitir en el segundo trimestre de gestación la regulación estatal que tienda a proteger la salud de la mujer, admitiéndose, incluso, la constitucionalidad de una prohibición estatal expresa de abortar durante el último trimestre, con la única excepción de los supuestos en que fuera necesario para proteger la salud o la vida de la mujer embarazada ${ }^{87}$.

Aunque, sin duda, lo más cuestionable de la decisión de Planned Parenthood of Southeastern Pennsylvania v. Casey, es la adopción de un nuevo test para las restricciones abortivas estatales anteriores a la viabilidad del feto, al sustituir el strict scrutiny ${ }^{88}$, esto

87505 U.S. 833, 846 (1992). Desde una perspectiva crítica con la reducción del nivel de protección que Casey representa respecto a Roe, vid. LAW, S., «Abortion Compromise-Inevitable and Impossible», University of Illinois Law Review, 1992, págs. 921-941.

88 La noción de «niveles de escrutinio judicial», incluyendo el strict scrutiny, se introdujo en la nota 4 del caso United States v. Carolene Products (1938), en el contexto del New Deal. El llamado strict scrutiny es el estándar más riguroso de control judicial utilizado por los tribunales de los Estados Unidos para revisar la legislación federal y estatal, que pondera un interés público esencial frente a un derecho fundamental o principio constitucional con el que entra en conflicto. El Strict scrutiny se plantea en dos contextos básicos: cuando se infringe un derecho fundamental, especialmente los enumerados en el Bill of Rights y los que el Tribunal Supremo ha considerado un derecho fundamental protegido por el concepto de libertad o la cláusula del debido proceso de la Decimocuarta Enmienda; o cuando la acción del gobierno consiste en el uso de una «clasificación sospechosa», tales como la raza o el origen nacional, que puede provocar su inconstitucionalidad en virtud de la cláusula de igual protección de la Decimocuarta Enmienda. Para pasar el strict scrutiny, la ley o política estatal debe satisfacer tres exigencias: en primer lugar, debe justificarse por un interés público necesario o esencial (compelling gobernmental interest), como la seguridad nacional, preservar la vida de varias personas, y no violar explícitamente garantías constitucionales expresas. En segundo lugar, la ley o política estatal debe concebirse para alcanzar ese objetivo o interés (narrowly tailored). Si la acción del gobierno es excesiva (overbroad) o no alcanza aspectos fundamentales del interés esencial (underinclusive), entonces no se considera estrictamente adaptada al interés estatal. Por último, la ley o política debe ser el medio menos restrictivo para la consecución de ese interés, es decir, que no puede haber otra forma menos restrictiva para conseguir eficazmente el interés público esencial. Por todo, las restricciones gubernamentales sobre los derechos fundamentales que se someten a un escrutinio riguroso son más frecuentemente declaradas inconstitucionales, de los diversos estudios vid. WINKLER, A., «Fatal in Theory and Strict in Fact: An Empirical Analysis of Strict Scrutiny in the Federal Courts», Vanderbilt Law Review, vol. 59, 2006, págs. 793-871. 
es, el examen judicial riguroso del interés estatal esencial en conflicto (compelling state interest) con el ejercicio del derecho fundamental, aplicado en Roe v. Wade, por el llamado «undue burden standard», que sólo admite la inconstitucionalidad de la regulación estatal cuando su propósito o efecto es obstaculizar sustancialmente la decisión de la mujer de abortar ${ }^{89}$, lo que ha abierto la puerta a una jurisprudencia vacilante. En efecto, ocho años más tarde, en Stenberg v. Carbart (2000) el Tribunal de Apelación del Octavo Circuito anuló una ley de Nebraska ${ }^{90}$ que prohibía la aplicación del método abortivo llamado «aborto por parto parcial» (partial-birth abortion) a partir del segundo trimestre de gestación, considerándolo una vulneración de los estándares fijados en Roe v. Wade y Planned Parenthood v. Casey. Expresando la opinión mayoritaria, el juez Breyer afirmaba que la prohibición del Estado de Nebraska violaba los precedentes de Roe y Casey al no incluir como excepción la preservación de la salud de la embarazada y al imponer una carga injustificada sobre la mujer para decidir el aborto ${ }^{91}$. Sin embargo, en 2007 el Tribunal Supremo confirmó, en una reñida decisión cinco a cuatro, la constitucionalidad de la Partial-Birth Abortion Ban Act aprobada por el Congreso en $2003^{92}$. Aplicando de manera distorsionada el undue burden test, el Tribunal afirmó en Gonzales v. Carbart ${ }^{93}$ que la aplicación de este tipo de técnicas de interrupción del embarazo no eran médicamente necesarias y no tenía porqué contemplarse excepción alguna que permitiera su aplicación en los casos de riesgo para la salud de la mujer, desapareciendo en la argumentación del Tribunal cualquier referencia al derecho a la autonomía reproductiva de la mujer, resurgiendo, de nuevo, los atávicos fantasmas del discurso paternalista, y negándose, incluso, como se afirmaba en el voto discrepante del juez Ginsburg, al que se unen los jueces Breyer, Souter y Stevens, las exigencias derivadas de la igual protección de la ley en virtud de la equal protection clause de la Decimocuarta Enmienda ${ }^{94}$. Desconoce así el propio Tribunal Supremo las decisiones mayoritarias previas de Roe y Casey, que exigen que los supuestos de aborto sean resueltos

89505 U.S. 833, 837 (1992). El «undue burden standard» es un test utilizado desde finales del siglo XIX por el Tribunal Supremo de los Estados Unidos en la revisión judicial de las leyes, que establece que la legislación estatal es inconstitucional si impone indebidamente cargas o gravámenes que no son útiles para alcanzar el objetivo permitido. El test fue utilizado por la jueza O'Connor en su voto discrepante del caso City of Akron v. Akron Center for Reproductive Health, 463 U.S. 416 (1983), como una alternativa al strict scrutiny aplicado en Roe v. Wade. El test es aplicado más tarde por la mayoría del Tribunal Supremo en el caso Planned Parenthood v. Casey, en el que el juez Stevens señaló que el gravamen puede ser indebido, bien porque es muy severo o porque carece de una justificación racional legítima, 505 U.S. 833, 920 (1992). Desde una postura crítica con el «undue burden estandard» vid. MetzGer, G. E., «Unburdening the Undue Burden Standard: Orienting 'Casey' in Constitutional Jurisprudence», Columbia Law Review, vol. 94, núm. 6, 1994, págs. 2025-2090; BROwNSTEIN, A., «How Rights Are Infringed: The Role of Undue Burden Analysis on Constitutional Doctrine», Hastings Law Journal, vol. 45, 1994, págs. 867-959.

90 Neb. Rev. Stat. Ann. § 28-328(1) (Supp. 2003).

91 Stemberg v. Carhart, 530 U.S. 914 (2000).

9218 U.S.C. $\$ 1531$.

93127 S.CT. 1610 (2007). De los numerosos estudios, vid. BRIDGES, K. M., «Capturing the Judiciary: Carhart and the Undue Burden Standard», Washington and Lee Law Review, vol. 67, 2010, págs. 915-984; SIEGEL, R. B., «Dignity and the Politics of Protection: Abortion Restrictions Under Casey/Carhart», Yale Low Journal, vol. 117, 2008, págs. 1694 y ss.; GARrow, D. J., «Significant Risks: Gonzales v. Carhart and the Future of Abortion Law», The Supreme Court Review, 2007, págs. 1-50.

94 Gonzales v. Carbart, 127 S. Ct. 1610, 1641 (2007) (Ginsburg, J., dissenting). 
en relación con el interés de la igual libertad de elección y autonomía de la mujer y conforme al derecho fundamental a la privacidad garantizado por la Decimocuarta Enmienda ${ }^{95}$.

Realmente, esta vacilante jurisprudencia de Tribunal Supremo no es extraña en el diacrónico proceso de conformación del derecho fundamental a la privacidad amparado por la libertad sustantiva que garantiza la cláusula del debido proceso legal de la Decimocuarta Enmienda. En efecto, en 1986 la opinión mayoritaria del Tribunal había negado protección a la conducta sexual privada en el caso Bowers v. Hardwick, admitiendo la constitucionalidad de las previsiones legislativas del Estado de Georgia que criminalizaban la práctica de la sodomía en el propio domicilio al no estar protegida por el sustantivo proceso legal de la Decimocuarta Enmienda ${ }^{96}$. Sin embargo, oponiéndose a la decisión mayoritaria, el juez Blackmun consideraba en su voto discrepante, junto con los Jueces Brennan, Marshall y Stevens, que la intimidad sexual en el domicilio privado constituye el núcleo "of the Constitution's protection of privacy» ${ }^{97}$. Hasta el 26 de junio de 2003 la mayoría del Tribunal Supremo, expresada por el Juez Kennedy, no admitió la opinión discrepante del juez Blackmun en Bowers, afirmando en el caso Lawrence et al. v. Texas que la Constitución reconoce la libertad de elegir la opción sexual y de ejercerla en la intimidad de los hogares sin la intromisión del Estado, de ahí que las relaciones sexuales consentidas entre personas adultas del mismo sexo en el ámbito privado estén amparadas por la libertad sustantiva que garantiza la cláusula del debido proceso legal de la Decimocuarta Enmienda ${ }^{98}$.

Incluso, la protección de la libertad de elección individual como núcleo intangible del derecho fundamental a la privacidad derivado del debido proceso legal sustantivo de la Decimocuarta Enmienda ha alcanzado los supuestos más extremos, como son la decisión sobre la propia muerte, esto es, si a través de él queda amparado constitucionalmente un determinado «derecho a morir» (the right to die $)^{99}$. Ámbito que ha mostrado también una jurisprudencia vacilante. Así, en 1990, en el caso Cruzan v. Director, Missouri Dep't. of Health ${ }^{100}$,

95 De la diversa doctrina crítica con la decisión del Tribunal en Gonzales v. Carhart, vid. IveY, R., «Destabilizing Discourses: Blocking and Exploiting a New Discourse at Work in Gonzales V. Carhart», Virginia Law Review, vol. 94, 2008, págs. 1451-1508; SuTER, S. M., «The 'Repugnance' Lens of Gonzales v. Carhart and Other Theories of Reproductive Rights: Evaluating Advanced Reproductive Technologies», The George Washington Law Review, vol. 76, 2008, págs. 1514 y ss.

96478 U.S. 186 (1986).

97478 U.S. 186, 208 (1986) (Blackmun, H., dissenting). Desde una perspectiva crítica con la decisión mayoritaria, vid. Rubenfeld, J., «The Right of Privacy», Harvard Law Review, vol. 102, 1989, págs. 737-807.

98539 U.S. 558 (2003). De la abundante doctrina sobre la conocida sentencia, vid. RiCHARDS, D. A. J., The Sodomy Cases: Bowers v. Hardwick and Lawrence v. Texas, University of Kansas, Lawrence, 2009; TRIBE, L. H., «Lawrence v. Texas: The 'Fundamental Right' that Dare Not Speak Its Name», Harvard Law Review, vol. 117, núm. 6, 2004, págs. 1893-1955; Sunstein, C. R., «What Did Lawrence Hold? Of Autonomy, Desuetude, Sexuality, and Marriage», Supreme Court Review, vol. 2003, págs. 27-74.

99 De los diversos estudios, vid. ALLEN, M. P., «The Constitution at the Threshold of Life and Death: A Suggested Approach to Accommodate an Interest in Life and a Right to Die», American University Law Review, vol. 53, 2004, págs. 971-1020; SunsteIn, C. R., «The Right to Die», Yale Law Journal, vol. 106, 1997, págs. 1123-1163; FliCK, M. R., «The Due Process of Dying», California Law Review, vol. 79, 1991, págs. 11211167; Kamisar, Y., «When Is There a Constitutional 'Right to Die'? When Is There No Constitutional 'Right to Live'?», Georgia Law Review, vol. 25, 1991, págs. 1203-1242.

100497 U.S. 261 (1990). En el voto discrepante del juez Brennan, al que se unen los jueces Marshall y Blackmun, se afirma que el derecho a rechazar el tratamiento médico es un derecho fundamental al afectar a 
el Tribunal Supremo, en una reñida decisión cinco a cuatro, no reconoció el derecho de los padres de una mujer en estado vegetativo durante ocho años tras un accidente a decidir sobre la retirada del tratamiento médico que le permitía vivir artificialmente, negnado la mayoría del Tribunal que el derecho a rechazar el tratamiento médico fuese una manifestación del derecho fundamental a la privacidad amparado por la clausula del debido proceso de la Decimocuarta Enmienda, aunque diversos Tribunales estatales de New Jersey, Florida y Massachusetts lo habían fundamentado en el derecho a la privacidad ${ }^{101}$.

Seis años más tarde, en 1996, el Tribunal de Apelación del Noveno Circuito reconoció en Compassion in Dying v. Washington un derecho constitucional al suicidio médicamente asistido en determinadas circunstancias, afirmándose que decisiones previas del Tribunal Supremo como Pierce, Griswold y Roe permiten sostener un derecho constitucional a decidir sobre la propia muerte, amparable por el debido proceso sustantivo de la Decimocuarta Enmienda, porque la Constitución representa el baluarte de la libertad individual frente a la intromisión del poder gubernamental arbitrario, que no puede imponer su voluntad en un asunto tan central para la autonomía y dignidad de la persona ${ }^{102}$. Cuando el caso llega al Tribunal Supremo en 1997, su presidente, el juez Rehnquist, al expresar la opinión del Tribunal afirma en Washington v. Glucksberg que aunque la cláusula del debido proceso garantiza algo más que un procedimiento judicial imparcial, y la libertad que protege abarca más que la ausencia de restricciones físicas, puesto que además de las libertades específicas protegidas por Bill of Rights, la libertad consagrada de modo especial por la cláusula del debido proceso incluye el derecho a casarse (Loving $v$. Virginia) $)^{103}$, a tener hijos (Skinner v. Oklahoma ex rel. Williamson) ${ }^{104}$ y decidir sobre la educación y la crianza de éstos (Meyer $v$. Nebraska; Pierce v. Society of Sisters) ${ }^{105}$, el derecho a la privacidad marital (Griswold v. Connecticut) ${ }^{106}$, al uso de anticonceptivos (Eisenstadt v. Baird $)^{107}$ y el derecho al aborto (Roe v. Wade; Planned Parenthood of Southeastern Pennsylvania v. Casey $)^{108}$, incluso, se había planteado si la cláusula del debido proceso podría amparar el derecho a no recibir un tratamiento médico que no se desea para salvar la vida (Cruzan v. Director, Missouri Dep't. of Health) ${ }^{109}$, sin

uno de los derechos básicos de la persona, enraizado en la historia y la tradición de la nación norteamericana, que prevalece frente a cualquier interés estatal en la preservación de la vida, 497 U.S. 261, 270 (1990). (Brennan, J., dissenting). De los diversos estudios, vid. SuHr, J. N., «Cruzan v. Director, Missouri Department of Health: A Clear and Convincing Call for Comprehensive Legislation to Protect Incompetent Patients' Rights», The American University Law Review, vol. 40, 1991, págs. 1477-1519; MAYO, Th. Wm., «Constitutionalizing the 'Right to Die'», Maryland Law Review, vol. 49, 1990, págs. 103-155.

101 Entre otros, vid. Foody v. Manchester Memorial Hosp., 40 Conn. Supp. 127, 132, 482 A.2d 713, 717 (1984); Satz v. Perlmutter, 362 So. 2d 160, 162 (Fla. Dist. Ct. App. 1978); Superintendent of Belchertown State School v. Saikewicz, 373 Mass. 728, 739-40, 370 N.E.2d 417, 424 (1977); Lane v. Candura, 6 Mass. App. 377, 37879, 376 N.E.2d 1232, 1233 (1978); In re Quinlan, 70 N.J. 10, 38-41, 51, 355 A.2d 647, 662-64, 669 (1976) certiorari denegado en 429 U.S. 922 (1976). Al respecto, vid. EATON, Th. A., y LARsOn, E. J., «Experimenting with the 'Right to Die' in the Laboratory of the States», Georgia Law Review, vol. 25, 1991, págs. 1253-1326.

102 Compassion in Dying v. Washington, 79 F. 3d 790, 798 (9 ${ }^{\text {th }}$ Circuit, 1996).

103388 U.S. 1 (1967).

104316 U.S. 535 (1942).

105262 U.S. 390 (1923); 268 U.S. 510 (1925).

106381 U.S. 479 (1965).

107405 U.S. 438 (1972).

108410 U.S. 113 (1973); 505 U.S. 833 (1992).

109497 U.S. 261 (1990). 
embargo, el Tribunal concluye que el derecho al suicidio asistido no constituye un interés fundamental de la libertad protegida por la cláusula del debido proceso de la Decimocuarta Enmienda ${ }^{110}$.

Con esta vacilante jurisprudencia, no sorprende que en el conocido caso Schiavo la retirada del sistema de nutrición que mantenía en una vida puramente artificial a Terri Shiavo desde 1990 generase una dilatada batalla judicial entre el marido y los padres de Terri en el Estado de Florida durante más de 7 años ${ }^{111}$, que se adoptase una ley específica por el Gobernador de Florida para mantenerla con vida en 2003, la llamada «Ley Terri» (Terri's Law) ${ }^{112}$, declarada inconstitucional por el Tribunal Supremo de Florida por tratarse de una delegación del poder legislativo contraria a la separación de poderes y a la integridad del sistema constitucional ${ }^{113}$, aunque el Tribunal no se pronunció expresamente sobre el derecho a la privacidad reconocido en la sección 23 del artículo 1 de la Constitución del Estado de Florida ${ }^{114}$, que, incluso, se aprobara una Ley específica del Congreso de los Estados Unidos en 2005 (An Act for the Relief of the Parents of Theresa Marie Schiavo ${ }^{115}$, y que, finalmente, el Tribunal Supremo rechazara pronunciarse sobre el caso ${ }^{116}$, relegándose, como apuntara la jueza O'Connor en Cruzan, la protección de estos ámbitos de libertad individual al «laboratorio de los Estados» ${ }^{117}$

Con todo, a lo largo de sesenta años, desde el voto discrepante del juez Harlan en Poe v. Ullman ${ }^{118}$ (1961), el concepto de libertad sustantiva de la cláusula del debido proceso legal de la Decimocuarta Enmienda ha permitido al Tribunal Supremo norteamericano garantizar el respeto de la libertad individual mediante la paulatina inducción constitucional de un fundamental right to privacy. Por esto no extraña que la centenaria formulación de la privacidad de Warren y Brandeis no sólo haya enraizado en la tradición constitucional norteamericana de la segunda mitad del siglo XX, sino que — como se analiza a continuación-continúe emergiendo a la hora de delimitar los ámbitos protegidos constitucionalmente frente a la obtención y utilización de información personal en la so-

110521 U.S. 702, 720 (1997). Considerando que la decisión del tribunal es errónea y defendiendo que las leyes que prohíben el suicidio asistido violan el derecho a la privacidad, vid. CHEMERINSKY, E., «Washington v. Glucksberg Was Tragically Wrong», Michingan Law Rewiew, vol. 106, 2008, págs. 1501-1516.

111 Vid. In re Guardianship of Schiavo, 780 So. 2d 176,177 (Fla. Dist. Ct. App. 2001); Bush v. Schiavo, 885 So. 2d 321,326-28 (Fla. 2004); In re Guardianship of Schiavo, No. 90-2908-GD-003, 2005 WL 459634 (Fla. Cir. Q. Feb. 25, 2005).

1122003 Fla. Laws 418

113 Bush v. Schiavo, 885 So. 2d 321 (Fla. 2004).

114 «Sección 23. Derecho a la privacidad. Toda persona física tiene derecho a estar solo y no sufrir injerencias de la Administración en su esfera privada, salvo disposición en contrario. Esta sección no limitará el derecho de acceso a los archivos públicos y reuniones previstas por ley», Sección 23, artículo 1, Constitución del Estado de Florida.

115 Pub. L. No. 109-3, 119 Stat. 15 (2005). Al respecto vid. Samaha, A. M., «Undue Process: Congressional Referral and Judicial Resistance in the Schiavo Controversy», Constitutional Commentary, vol. 22, 2005, págs. 505-528.

116 Sobre el caso vid. Clark, A. E., «The Right to Die: The Broken Road from Quinlan to Schiavo», Loyola University Chicago Law Journal, vol. 37, 2006, págs. 385-405; CARTER, S., O., «The (Surprising) Truth about Schiavo: A Defeat for the Cause of Autonomy», Constitutional Commentary, vol. 22, 2005, págs. 383-404.

117497 U.S. 261, 292 (1990) (O’Connor, J., concurring).

118 Poe v. Ullman, 367 U.S. 497, 542, 543 (1961) (Harlan, J., dissenting). 
ciedad tecnológica avanzada de principios del siglo $\mathrm{XXI}^{119}$, esto es, la llamada «informational privacy».

\section{LA PROTECCIÓN DE LA PRIVACIDAD EN LA SOCIEDAD TECNOLÓGICA: EL DERECHO CONSTITUCIONAL A LA «INFORMATIONAL PRIVACY»}

Sin duda, en la Sociedad de la Información y del Conocimiento de principios del siglo XXI, la recopilación, almacenamiento, tratamiento y utilización telemática de información personal alcanza relevancia central para la protección de la esfera privada, hasta el punto de que podría decirse que el bien jurídico protegido por el derecho a la privacidad es fundamentalmente la información personal, dando lugar a la reclamación de un nuevo ámbito de protección constitucional de la privacidad bajo la denominación de «informational privacy». Bajo esta nueva dimensión, se ha definido el derecho a la privacidad como el poder de controlar el flujo de información personal ${ }^{120}$ y como el derecho a decidir cuándo, cómo y en qué medida la información personal es comunicada a otros, proceso de autodeterminación personal que ha de integrarse asimismo en los procesos comunicativos y participativos en los que interviene el individuo ${ }^{121}$, afirmándose que el principal atributo de un efectivo derecho a la privacidad es la capacidad de la persona de controlar el flujo de información que le concierne, capacidad esencial para el establecimiento de relaciones sociales y el mantenimiento de la libertad personal ${ }^{122}$, de ahí que se haya defendido una regulación estatal generalizada que asegure el control efectivo sobre el flujo de información personal, formulándose asî un modelo estatal que interviene en el ámbito informacional por ser éste un valor constitutivo esencial del nuevo paradigma sociológico de principios del siglo $\mathrm{XXI}^{123}$.

En esta línea, el Congreso norteamericano ha aprobado numerosas disposiciones legislativas con el objeto de regular eventuales invasiones de la «informational privacy», especialmente a partir de 1974 en que se aprueba la primera ley general de protección de la información personal en poder de las Agencias Federales de los Estados Unidos, la llamada Privacy Act ${ }^{124}$, que modifica la Freedom of Information Act (FOIA) de 1966, que regula con carácter general el acceso de los ciudadanos a la información disponible en los archivos y registros públicos de las Agencias Federales, eximiendo al Gobierno de hacer

119 Como ha señalado R. GELLMAN, en muchos sentidos la batalla por la protección de la esfera privada en el siglo XX ha sido una lucha por adaptar los principios de la privacidad a los constantes avances tecnológicos, vid. Technology and Privacy: The New Landscape, Philip E. Agre y Marc Rotenberg (eds.), The MIT Press, Cambridge, 1997, pág. 203.

120 Cfr. Fried, C., «Privacy», The Yale Law Journal, vol. 77, 1967-1968, págs. 475-493.

121 Cfr. Westin, A. F., Privacy and Freedom, Atheneum, New York, 1967, pág. 7.

122 Cfr. Miller, A. R., The Assault on Privacy: Computers, Data Banks and Dossiers, Ann Arbor, University of Michigan Press, 1971, pág. 25; también de Miller «Personal Privacy in the Computer Age: The Challenge of a new Technology and Information Oriented Society», Michigan Law Review, vol. 67, 1969, págs. 1089-1246, especialmente pág. 1109.

123 Cfr. Schwartz, P. M., «Privacy and Democracy in Cyberspace», Vanderbilt Law Review, vol. 52, 1999, págs. 1609-1701; y también de SCHWARTZ, «Internet, Privacy and the State», Connecticut Law Review, vol. 32, 2000, págs. $815-859$.

124 Privacy Act, 5 U.S.C. \$552a, Section 2. 
públicos sus archivos cuando esto suponga una injustificada invasión en la información personal ${ }^{125}$. Desde entonces se han adoptado numerosas leyes federales que regulan la protección de información personal en contextos específicos ${ }^{126}$, tales como los servicios financieros [en la Right to Financial Privacy Act (RFPA) de 1978, la Financial Services Modernization Act de 1999, conocida como la Gramm-Leach-Bliley Act (GLBA), y la Fair and

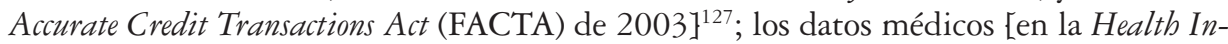
surance Portability and Accountability Act (HIPAA) de 1996]; ${ }^{128}$ y más recientemente la privacidad genética [en la Genetic Information Nondiscrimination Act (GINA) de 2008 ${ }^{129}$. Destacando igualmente la protección de la información personal en las comunicaciones electrónicas, especialmente en la Cable Communication Policy Act (CCPA) de 1984, la Electronic Communications Privacy Act (ECPA) de 1986, la Telecomunications Act de 1996, la Children's On-line Privacy Protection Act (COPPA) de 1998 y la E-Government Act de $2002^{130}$

Así, en los Estados Unidos la protección de la llamada «informational privacy» está regulada sectorialmente en previsiones legales federales de carácter fragmentario, que contemplan numerosas excepciones y adolecen de importantes lagunas, de ahí que diversa doctrina norteamericana venga defendiendo el reconocimiento expreso por el Tribunal Supremo de un derecho constitucional a la «informational privacy» ${ }^{131}$. Realmente, ya en 1977 el Tribunal intentó ampliar el ámbito constitucional de protección del derecho a la privacidad al esbozar en el caso Whalen $v$. Roe el llamado «constitutional right to informational privacy». En Whalen se cuestionaba la constitucionalidad de la legislación de Nueva York que requería se remitiese a las autoridades estatales competentes el nombre y la dirección de los pacientes que recibían prescripciones facultativas de drogas con fines médicos, como el opio y sus derivados, metadona y anfetaminas, al objeto de su inclusión en una base de datos estatal centralizada. Aunque el Tribunal declaró la constitucionalidad de la ley estatal, al considerar que el interés del Estado de Nueva York en adoptar medidas tendentes al control de la distribución de drogas peligrosas era un legítimo ejercicio del poder policial estatal, sin embargo, el Tribunal Supremo afirmó el derecho de la per-

125 Freedom of Information Act, 5 U.S.C. \$552.

126 Para un extenso y detallado estudio del marco normativo que directa o indirectamente afecta a la protección de la privacidad, vid. Solove, D. J., Rotenberg, M. y Schwartz, P. M., Information Privacy Law, 3rd ed., Aspen Publishers, New York, 2009; Schwartz, P. M., y Solove, D. J., Information Privacy: Status and Regulations 2010-2011, Aspen Publishers, 2009.

127 Right to Financial Privacy Act, 12 U.S.C. \$ 3401 y ss.; Financial Services Modernization Act, 15 U.S.C. $\$ 6801$ y ss.; Fair and Accurate Credit Transactions Act, Public Law, 108-159.

128 Health Insurance Portability and Accountability Act, Public Law 104-191, 110 Stat. 1936.

129 An Act to Probibit Discrimination on the Basis of Genetic Information with Respect to Health Insurance and Employment (GINA), Public Law 110-233, 122 Stat. 881.

130 Cable Communication Policy Act, 47 U.S.C. $\$ 551$ y ss.; Electronic Communications Privacy Act, 18 U.S.C. $\$$ \$2510-2520 2701-2709; Telecommunications Act, 47 U.S.C. \$222; Children's On-line Privacy Protection Act, 15 U.S.C. \$\$6501-6506; E-Government Act, 44 U.S.C. $\$ 101$.

131 Vid. Flaherty, D. H., «On the Utility of Constitutional Rights to Privacy and Data Protection», Case Western Reserve Law Review, vol. 41, 1991, págs. 831-855, especialmente pág. 852; CHLAPOWSKI, F. S., «The Constitutional Right to Informational Privacy», Boston University Law Review, vol. 71, 1991, págs. 133 y ss., especialmente pág. 135; Turkington, R. C., «Legacy of the Warren and Brandeis Article: The Emerging Unencumbered Constitutional Right to Informational Privacy», Northern Illinois University Law Review, vol. 10, 1989-1990, págs. 479-520, especialmente págs. 496-502. 
sona a mantener la reserva de su información personal, señalando que la «zona de privacidad» protegida constitucionalmente no sólo ampara la autonomía individual en la toma de decisiones importantes sino también el «interés» individual en evitar la revelación de asuntos personales ${ }^{132}$. Ese mismo año, el Tribunal Supremo volvió a pronunciarse sobre el interés constitucional en la protección de la información personal en Nixon v. Administrator of General Service, en el que se instaba al Presidente Nixon a revelar comunicaciones personales a los archivistas del Gobierno en atención al importante interés público del material reservado, afirmándose que se había definido como un elemento de la privacidad el «interés individual» en evitar la divulgación de asuntos personales ${ }^{133}$.

Aunque el Tribunal Supremo no define propiamente el alcance constitucional del derecho, sin embargo, como han manifestado diversos Tribunales de Circuito ${ }^{134}$, los casos que se citan en Whalen - Pierce v. Society of Sisters, Griswold v. Connecticut y Roe v. Wade - inducen a pensar que el Tribunal Supremo deriva el derecho a la informational privacy del debido proceso sustantivo garantizado por la Decimocuarta Enmienda ${ }^{135}$. En este sentido, tres años más tarde, en 1980, el Tribunal de Apelaciones del Tercer Circuito señaló en United States $v$. Westinghouse Electric Corporation que aunque la completa medida de la protección constitucional del derecho a la privacidad no había sido todavía delimitada, sin embargo, refiriéndose a Whalen afirma que se extiende a dos tipos de intereses, y que el que se sustancia en el caso pertenece al interés individual en evitar la divulgación de información personal. Para su resolución, el Tribunal formula un «balancing test» que coadyuva a ponderar los bienes jurídicos en conflicto, esto es, el interés individual en mantener la reserva de la información personal frente a un interés general más relevante en su divulgación (compelling governmental interest), señalando que los elementos a considerar para decidir si una intromisión en la privacidad individual está justificada son el tipo de datos solicitados, la información que contiene o puede contener, el potencial

132 «Los casos catalogados de protección de la 'privacidad' han involucrado realmente al menos dos clases diferentes de intereses. Uno es el interés individual en evitar la revelación de asuntos personales, y otro el interés en la autonomía individual para tomar cierta clase de decisiones importantes [... ] Sin embargo, no hemos dicho la última palabra sobre estos asuntos. Somos conscientes de la amenaza para la privacidad implícita en la acumulación de gran cantidad de información personal en los bancos de datos informatizados y en otros enormes archivos del gobierno. La recaudación de impuestos, la distribución de los beneficios sociales y de la seguridad social, la administración de la salud pública, la dirección de las Fuerzas Armadas y el cumplimiento de las leyes penales, requiere el mantenimiento ordenado de gran cantidad de información, la mayoría de la cual es en esencia personal y potencialmente embarazosa o perjudicial si es revelada. El derecho a recopilar y usar tal tipo de datos con propósitos públicos está normalmente acompañado de una correspondiente obligación estatutaria o administrativa de evitar revelaciones injustificadas», Whalen v. Roe, 429 U.S. 589, 599-600, 605 (1977).

133433 U.S. 425, 457 (1977). En este sentido, vid. KANG, J., «Information Privacy in Cyberspace Transactions», Stanford Law Review, vol. 50, 1998, págs. 1193-1294, especialmente pág. 1230, nota 157. En sentido contrario, LIN afirma que el caso Nixon realmente refleja un debilitamiento del interés constitucional en la protección de la información personal, vid. «Prioritizing Privacy: A Constitutional Response to the Internet», op. cit., págs. 1125-1126.

134 Entre otros, vid. Kallstrom v. City of Columbus, 136 F.3d 1055, 1064 (6th Cir. 1998); Flanagan v. Munger, 890 F.2d 1557, 1570 (10th Cir. 1989); Mangels v. Pena, 789 F.2d 836, 839 (10th Cir. 1986).

135 En este sentido ver Froomkin, A. M., «Government Data Breaches», Berkeley Technology Law Journal, vol. 24, 2009, págs. 1019-1060, especialmente págs. 1046 y ss.; Solove, D. J. A., «A Taxonomy of Privacy», University of Pennsylvania Law Review, vol. 154, 2006, págs. 477-560, especialmente pág. 530. 
daño en una subsiguiente revelación no consentida, la existencia de garantías que prevengan revelaciones no autorizadas, el grado de necesidad de acceso, y si hay un mandato legal expreso, política pública u otro interés público reconocible que canalice el acceso. Aplicando el balancing test, el Tercer Circuito estableció que la información médica pertenece al ámbito de la privacidad merecedor de protección en la medida en que contiene datos íntimos de naturaleza personal, declarando que la solicitud de los archivos médicos de los trabajadores de una empresa al objeto de investigar posibles riegos para la salud en el ámbito laboral constituye una mínima intromisión en la privacidad de los empleados, exigiéndose la previa comunicación a los trabajadores al objeto de que puedan decidir sobre su revelación y utilización. Con todo, el Tribunal avisa de que el derecho no es absoluto, dado que razones de salud pública, por ejemplo, podrían justificar el acceso a información que la persona preferiría mantener confidencial ${ }^{136}$.

Se inicia así una línea jurisprudencial a favor del derecho constitucional a la informational privacy seguida por Tribunales inferiores ${ }^{137}$. Sin embargo, los Tribunales de Circuito difieren considerablemente en la definición del alcance del derecho a la informational privacy. Así, el Sexto Circuito, entre otros, ha interpretado el derecho de forma restrictiva, reconociéndolo sólo cuando la invasión de la privacidad implica un derecho fundamental o un derecho implícito en el concepto de libertad de la Decimocuarta Enmienda, protegiéndose solo la información de carácter personal que presenta una «dimensión» constitucional al implicar garantías constitucionales concretas o derechos de privacidad de carácter decisional ${ }^{138}$. En esta línea, los Tribunales han aplicado un exigente escrutinio $^{139}$ para admitir la constitucionalidad de la revelación de información personal contenida en archivos confidenciales médicos, como la vida sexual privada, la orientación sexual, los informes psicológicos o el padecimiento del SIDA ${ }^{140}$.

136 United States v. Westinghouse Electric Corporation, 638 F.2d 570 (3d Cir. 1980).

137 En Plante v. Gonzalez, 575 F.2d 1119, 1134 (5th Cir. 1978), se afirma que el Tribunal Supremo había reconocido claramente que la privacidad de los asuntos personales está protegida por la Constitución; en Barry v. City of New York, 712 F.2d 1554 (2d Cir. 1983), se confirma que cualquier duda existente después del caso Whalen v. Roe sobre el estatus constitucional del interés en evitar la revelación de asuntos personales fue disipada por Nixon v. Administrator of General Services; en Tavoulareas v. Wash. Post Co., 724 F.2d 1010, 1019 (C.A.D.C. 1984) se señala que decisiones recientes del Tribunal Supremo indican que el interés de un demandante en evitar la divulgación pública de información privada se fundamenta en la misma Constitución; en Slayton v. Willingham, 726 F.2d 631, 635 (10th Cir. 1984) se sostiene que el Tribunal Supremo reconoció expresamente el derecho constitucional a la informational privacy en Whalen v. Roe; en Flanagan v. Munger, 890 F.2d 1557, 1570 (10th Cir. 1989) se afirma que el Tribunal Supremo ha reconocido que el derecho constitucional a la privacidad protege el interés individual en impedir la divulgación por el gobierno de asuntos personales.

138 Vid. Overstreet v. Lexington-Fayette Urban County Government, 305 F3d 566, 574 (6th Cir 2002); Bloch v. Ribar, 156 F3d 673, 684 (6th Cir 1998); Kallstrom v. City of Columbus, 136 F3d 1055, 1062 (6th Cir 1998).

139 Para un detallado análisis de la aplicación del balancing test por los Tribunales de Circuito, vid. GILBERT, H. L., «Minors' Constitutional Right to Informational Privacy», University of Chicago Law Review, vol. 74, 2007, págs. 1375-1410; Turkington, R. C., «Legacy of the Warren and Brandeis Article: The Emerging Unencumbered Constitutional Right to Informational Privacy», op. cit., págs. 501-519; vid. también, CHLAPOwsKi, F. S., «The Constitutional Right to Informational Privacy», Boston University Law Review, vol. 71, 1991, págs. 133 y ss.

140 Entre otros, vid. Tucson Woman's Clinic v. Eden, 379 F.3d 531, 551 (9th Cir. 2004) (afirmándose que la previsión legal que permite al Estado el acceso al historial clínico de los abortos practicados viola el derecho a la privacidad de los pacientes); Powell v. Schriver, 175 F.3d 107, 111-112 (2d Cir. 1999) (sosteniéndose que un recluso transexual tiene derecho a la confidencialidad de los registros médicos); Doe v. Borough of Barrington, 729 F. Supp. 
Otro Tribunales de Circuito han interpretado el derecho constitucional a la informational privacy más ampliamente, protegiendo información personal que no afecta a libertades fundamentales, como los datos bancarios y financieros ${ }^{141}$ y el número de la seguridad social $^{142}$. Sin embargo, todos los Circuitos se han negado a conceder protección a los datos personales contenidos en registros públicos, como los arrestos policiales y las condenas judiciales, dado el carácter público o el interés general que revisten los mimos, aunque se protege la información confidencial relativa a las víctimas de los delitos ${ }^{143}$.

Y como se había establecido en Nixon v. Administrator of General Service, todos los Tribunales de Circuito sostienen que el derecho a la informational privacy no es absoluto, ponderándose el interés individual en la protección de la información personal frente al interés estatal en la adquisición o divulgación de esa información, aunque difieren en cuanto a la relevancia que otorgan al interés estatal. Así, el Cuarto, Sexto y Décimo Circuitos aplican un examen judicial riguroso (strict scrutiny) a las invasiones estatales de la informational privacy, aunque el Sexto Circuito solo reconoce una violación de la información personal cuando afecta a derechos fundamentales, exigiendo demostrar un interés estatal esencial (compelling state interest) para invadir derechos fundamentales a través de la revelación de información personal, mientras que el Cuarto Circuito también aplica un escrutinio riguroso para evaluar la divulgación estatal de la información personal que no afecta a derechos fundamentales ${ }^{144}$. El resto de los Tribunales de Circuito ha adoptado algún tipo de escrutinio intermedio, aplicándose por la mayor parte de los Circuitos el balancing test adoptado en United States v. Westinghouse Electric Corporation ${ }^{145}$.

376 (D.N.J. 1990) (considerándose una violación del derecho constitucional a la privacidad la relevación por la policía de que una persona padece el SIDA); Woods v. White, 689 F. Supp. 874, 876 (W.D. Wis. 1988) (declarándose que un prisionero tiene un derecho constitucional a la privacidad sobre sus archivos médicos); Carter v. Broadlawns Med. Ctr., 667 F. Supp. 1269 (S.D. Iowa 1987) (considerándose una violación del derecho constitucional a la privacidad que los hospitales permitan a los ministros eclesiásticos el acceso a los archivos médicos de sus pacientes).

141 Entre otros, vid. In re McVane, 44 F3d 1127, 1136-37 (2d Cir 1995); Fraternal Order of Police, Lodge No 5 v. City of Philadelphia, 812 F2d 105, 115 (3d Cir 1987); Walls v. City of Petersburg, 895 F2d 188, 194 (4th Cir 1990).

142 Vid. In re Crawford, 194 F3d 954, 958 (9th Cir 1999) (afirmándose que la divulgación pública de forma indiscriminada del número de la seguridad social puede implicar la vulneración del derecho constitucional a la informational privacy).

143 Vid. Paul P. v. Verniero, 170 F.3d 396, 404 (3d Cir. 1999) (declarándose que una ley que publica una lista de personas condenadas por agresiones sexuales — conocida como «Mengan's Law»— no viola la privacidad constitucional porque el interés del gobierno en prevenir agresiones sexuales es más relevante; Russell v. Gregoire, 124 F.3d 1079, 1094 (9th Cir. 1997) (declarándose igualmente que la Ley del estado de Washington similar a la «Megan's Law» no viola la privacidad constitucional porque la información recopilada y difundida por la mencionada Ley estaba ya públicamente disponible por lo que no estaba protegida constitucionalmente); Cline v. Rogers, 87 F.3d 176, 179 (6th Cir. 1996) (declarándose que no hay un derecho constitucional a la privacidad sobre los archivos criminales en tanto que la información sobre los arrestos y condenas son objeto de registro público); Scheetz v. The Morning Call, Inc., 946 F.2d 202, 207 (3d Cir. 1991) (declarándose que no hay derecho a la protección de la privacidad por la revelación de información contenida en los informes policiales).

144 Vid. Walls v. City of Petersburg, 895 F2d 188, 194 (4th Cir 1990); Kallstrom v. City of Columbus, 136 F3d 1055, 1062 (6th Cir 1998); Bloch v. Ribar, 156 F3d 673, 684 (6th Cir 1998); Anderson v. Blake, 469 F3d 910, 914 (10th Cir 2006).

145 Entre otros, vid. Daury v. Smith, 842 F2d 9, 13 (1st Cir 1988); Doe v. City of New York, 15 F3d 264, 269 (2d Cir 1994); Plante v. Gonzalez, 575 F2d 1119, 1134 (5th Cir 1978); Denius v. Dunlap, 209 F3d 944, 955 (7th Cir 2000); Tucson Woman's Clinic v. Eden, 379 F3d 531, 551 (9th Cir 2004); Hester v. City of Milledgeville, 777 F2d 1492, 1497 (11th Cir 1985). 
Por todo, los diferentes estándares judiciales aplicados por los Tribunales de Circuitos, unido al diferente alcance en cuanto a los distintos tipos de información personal protegida, han dificultado que en última instancia se otorgue una efectiva protección frente a las invasiones estatales de la «informational privacy». No obstante, a principios de 2011, después de más de treinta años transcurridos desde Whalen y Nixon, el Tribunal Supremo ha tenido la oportunidad de pronunciarse de forma definitiva sobre el alcance del derecho a la informational privacy en el caso NASA v. Nelson, aunque ha resultado, lamentablemente, una oportunidad perdida. En 2007, conforme a lo previsto en la Directiva Presidencial de Seguridad Nacional 12 (Homeland Security Presidential Directive-12) de 2004, los empleados contratados en el Instituto de Tecnología de California de la NASA (National Aeronautics and Space Administration) fueron obligados a responder unos formularios normalizados que preguntaban si habían utilizado, poseído, suministrado o fabricado drogas ilegales en el último año, estando obligados los empleados que respondieran afirmativamente a informar sobre cualquier tratamiento o asesoramiento recibido. Una vez que el formulario había sido completado y que el empleado había autorizado al Gobierno obtener más información, se enviaba un cuestionario a quiénes habían otorgado credenciales a favor del empleado, preguntándoles si tenían motivos para poner en duda la honestidad o fiabilidad del empleado, si conocían que hubiera violado la ley, sobre su integridad financiera, posible abuso de alcohol y/o drogas, su estabilidad mental y emocional y, en general, sobre cualquier comportamiento o conducta del empleado, estando la información obtenida sujeta a la protección de la Privacy Act de 1974. Dos meses antes de finalizar el procedimiento, cerca de treinta empleados presentaron una demanda ante el Noveno Circuito denunciando que la comprobación de sus antecedentes violaba su derecho constitucional a la informational privacy y que la Privacy Act no proporcionaba un control suficiente frente a divulgaciones indebidas ${ }^{146}$.

El Tribunal Supremo resuelve el caso NASA v. Nelson el 16 de enero de 2011. Al exponer la opinión del Tribunal, el juez Alito afirma que aunque en Whalen y Nixon el Tribunal se había referido al interés individual de relevancia constitucional en evitar la revelación de asuntos personales, y suponiendo, aunque sin decidirlo, que las investigaciones del Gobierno impugnadas en NASA v. Nelson implicasen un interés privado de relevancia constitucional, sin embargo — continúa Alito_ese interés, sea cual sea su alcance, no impide que el Gobierno plantee preguntas razonables en una investigación sobre antecedentes de sus empleados que está sujeta a las garantías que ofrece la Privacy Act frente a su eventual divulgación. Renuncia así el AltoTribunal a pronunciarse expresamente sobre el alcance del derecho constitucional a la informational privacy, llegando incluso el juez Scalia a afirmar abiertamente en su voto concurrente que no existe un derecho constitucional federal a la informational privacy ${ }^{147}$.

146 Nelson v. NASA, 506 F.3d 713, 715-16 (9th Cir. 2007). Para un estudio más detallado, vid. O’BrIEN, C. M., «Homeland Security Presidential Directive-12, Background Investigations, and Informational Privacy Rights», Mississippi Law Journal, vol. 80, 2010, págs. 299-353.

147 National Aeronautic and Space Administration et al. v. Nelson et al., 131 S.Ct. 746 (2011). On a Writ of Certiorari to the United States Court of Appeals for the Ninth Circuit, January 19, 2011. El Electronic Privacy Information Center (EPIC), presentó un amicus curiae, firmado por 27 expertos técnicos y juristas especialistas, que defienden el derecho a la protección constitucional de la informational privacy, alegando el reconocimiento del derecho por el Tribunal Europeo de Derechos Humanos, el Tribunal Federal Alemán, e, incluso, se cita la jurisprudencia del Tribunal Constitucional español, exponiéndose asimismo los problemas relacionados con la 
En definitiva, el Tribunal Supremo norteamericano parece anclado en el pasado y manifiesta una evidente resistencia a hacer frente al ineludible tratamiento constitucional complejo que exige la protección de los derechos de privacidad en la sociedad tecnológica avanzada de principios del siglo XXI, en la que el Estado dispone de tecnología y facultades para obtener, almacenar y utilizar información de carácter personal en amplias bases de datos, información que puede ser muy sensible, crucial para la reputación y el bienestar personal, cuya filtración puede generar daños irreparables, que, sin duda, deben ser evitados por la Constitución. Sin olvidar la amenaza que suponen las tecnologías destructivas de la privacidad individual implementadas gracias a la red telemática mundial que representa Internet ${ }^{148}$, cobrando cada vez mayor relevancia garantizar espacios efectivos de privacidad frente a la injerencia estatal, especialmente tras la legislación antiterrorista aprobada en los Estados Unidos, pues, sin duda, la conocida USA Patriot Act (USAPA) de 2001 y las reformas legislativas a que ha dado lugar ${ }^{149}$, así como la expansión de la vigilancia electrónica por los servicios de inteligencia regulados en la Foreign Intelligence Surveillance Act (FISA) de $1978^{150}$, han supuesto un claro retroceso en los niveles de protección de la privacidad alcanzados, generalizándose en aras de la seguridad nacional la interceptación de comunicaciones electrónicas de todo tipo en Internet ${ }^{151}$. De ahí que diversos autores sostengan, incluso, que la Constitución norteamericana por sí sola no dispone de mecanismos capaces de hacer frente a las tecnologías destructivas de la privacidad individual implementadas gracias a la red telemática mundial que representa Internet ${ }^{152}$. Con este panorama, parece que se están haciendo realidad las palabras del juez Douglas en Osborn v. United States, cuando vaticinaba en 1966 «es-

protección de los datos que plantea la Privacy Act, especialmente las doce excepciones contempladas en los llamados usos rutinarios (routine use exceptions), que permiten la revelación de información personal sin el consentimiento de su titular, las brechas de seguridad, y la competencia de la Agencia para definir sus propias excepciones, vid. National Aeronautic and Space Administration et al. v. Nelson et al., On a Writ of Certiorari to the United States Court of Appeals for the Ninth Circuit, Brief of Amici Curiae Electronic Privacy Information Center (EPIC) and Legal Scholar and Technical Experts in Support of the Respondents, August 9, 2010.

148 En este sentido, vid. LiN, E., «Prioritizing Privacy: A Constitutional Response to the Internet», op. cit., passim.

149 Uniting and Strengthening America by Providing Appropriate Tools Required to Intercept and Obstruct Terrorism Act (USA Patriot Act), Public Law, 107-156, 115 Stat. 272 (2001). Para su estudio, vid. Doyle, Ch., The Usa Patriot Act: A Legal Analysis, Congressional Research Service, The Library of Congress, 2002; WHITEHEAD, J. W. y ADEN, S. H., «Forfeiting 'Enduring Freedom' for 'Homeland Security': A Constitutional Analysis of the Usa Patriot Act and the Justice Department's Anti-Terrorism Initiatives», American University Law Review, vol. 51, 2002.

150 Foreign Intelligence Surveillance Act, 50 U.S.C. $\$ \$ 1801-18011$ (1978). Sobre este asunto, vid. JAEGER, P. T., et al., «The Impact of the USA Patriot Act on Collection and Analysis of Personal Information under the Foreign Intelligence Surveillance Act», Government Information Quarterly, vol. 20, 2003, págs. 295-314; BRADLEY, A. A., «Extremism in the Defence of Liberty?: The Foreign Intelligence Surveillance Act and the Significance of the U.S.A. Patriot Act», Tulane Law Review, vol. 77, 2002, págs. 465-493.

151 De los diversos estudios, vid. O’Donnel, M. J. «Reading for Terrorism: Section 215 of the USA Patriot Act and the Constitutional Right to Information Privacy», Journal of Legislation, vol. 31, 2004, págs. 4568; Madrinan, P. G., «Devil in the Details: Constitutional Problems Inherent in the Surveillance Provisions of the Usa Patriot Act of 2001», University of Pittsburgh Law Review, vol. 64, 2003, págs. 783-834.

152 En este sentido, vid. Froomkin, A. M., «The Death of Privacy?», Stanford Law Review, vol. 52, 2000, págs. 1461-1463, especialmente págs. 1540-1541; CATE, F. H., Privacy in the Information Age, Brookings Institution Press, Washington, D.C., 1997, págs. 66 y 68. 
tamos llegando rápidamente a la era de la no privacidad, donde todos están sujetos a vigilancia en todo momento» ${ }^{153}$. Era que no debería alcanzarse nunca, dada la fundamentalidad de la privacidad para la existencia misma del sistema democrático.

\section{CONSIDERACIONES FINALES. LA «FUNDAMENTALIDAD» DE LA PRIVACIDAD PARA EL SISTEMA DEMOCRÁTICO}

No puede dudarse de la dimensión fundamental que ha alcanzado la privacidad en el sistema constitucional de los Estados Unidos. El análisis del diacrónico proceso de conceptualización y protección constitucional que aquí se concluye revela la tendencia creciente a garantizar la privacidad como un bien fundamental en la escala de intereses jurídico-constitucionales. Intereses relacionados con el ámbito individual y formulados en términos de secreto, soledad, autonomía, desarrollo de la personalidad, libertad de elección en asuntos personales y control de la información personal, de manera que la privacidad es fundamento y garantía de libertades fundamentales, así los casos de escuchas telefónicas y vigilancia electrónica de la Cuarta Enmienda y las garantías frente a la autoincriminación de la Quinta Enmienda. Igualmente, los derechos al aborto o a la realización de prácticas homosexuales consentidas entre adultos se forjaron exigiendo ámbitos de privacidad amparados constitucionalmente por la libertad sustantiva de la cláusula del debido proceso de la Decimocuarta Enmienda. En consecuencia, el derecho a la privacidad es único en el sistema constitucional de los Estados Unidos, puesto que sólo puede concederse a expensas de otras libertades fundamentales reconocidas expresamente en la Constitución norteamericana, unidas y entrelazadas de forma inextricable por el mismo derecho a la privacidad. Así, la Primera, Cuarta, Quinta, Novena y Decimocuarta Enmiendas dan fundamento a distintas facetas de privacidad, de forma que constitucionalmente el derecho a la privacidad está vinculado a cuatro de las diez primeras Enmiendas, a cinco de las catorce primeras, y las «emanaciones derivadas de las zonas de penumbra» a todo el Bill of Rights ${ }^{154}$.

Con todo, una aproximación a la «fundamentalidad» de la privacidad no puede constreñirse exclusivamente a su dimensión individual o subjetiva, antes al contrario, la protección de la privacidad presenta igualmente una dimensión objetiva o social que coadyuva al avance del sistema democrático ${ }^{155}$. En efecto, el concepto moderno de libertad en su doble acepción de libertad autonomía y participación, sobre el que se asienta el sistema democrático, está especialmente fundamentado en el concepto de privacidad, en esa esfera de autonomía libre de toda injerencia estatal que garantiza el desarrollo de la per-

153 Osborn v. United States, 385 U.S. 323, 341 (1966) (Douglas, J., dissenting).

154 En este sentido vid. Brady, R., «From Court to Country: A Legal, Social and Political Analysis of Privacy in the U.S., 1965-1974», Honors Projects, Paper 4, 2007, pág. 7.

155 En esta línea, entre otros, vid. Solove, D. J., The Digital Person: Technology and Privacy in the Information Age, New York University Press, New York, 2004, especialmente págs. 57 y ss.; SCHWARTZ, P. M., «Beyond Code for Internet Privacy: Cyberspace Filters, Privacy Controls, and Fair Information Practice», Wisconsin Law Review, 2000, págs. 743-788, especialmente págs. 787-788; PosT, R. C., «The Social Foundations of Privacy: Community and Self in the Common Law Tort», California Law Review, vol. 77, 1989, págs. $957-$ 1010, especialmente págs. 1008-1009. 
sonalidad y de la identidad individual y, por tanto, la formación de ciudadanos libres e independientes capaces de participar plenamente en el debate público, reflejándose así la conexión ineludible entre la doble dimensión individual y social de la privacidad y su relación inexorable con la libertad, magistralmente analizada por George Orwell en 1984, su obra clásica frente al totalitarismo ${ }^{156}$.

En definitiva, la protección de la privacidad constituye presupuesto fundacional de la existencia de una ciudadanía activa y participativa, esencia misma del Estado democrático. Si una vida privada al amparo de injerencias no deseables permite el libre desarrollo de la personalidad, si la protección de la privacidad fomenta el desarrollo de la autonomía individual y la autodeterminación personal, aspectos todos que en última instancia promueven una ciudadanía más activa y participativa, su protección es igualmente un criterio determinante del carácter democrático de toda sociedad. Una sociedad vigilada se transforma en una sociedad conformista y pasiva que aliena al mismo sistema democrático. La protección de la privacidad individual contribuye así a la vitalidad de la esfera pública y por tanto al dinamismo político y social. De ahí que la protección constitucional de las zonas de privacidad que aseguran nuestra autonomía individual sea, a la vez, condición y garantía del sistema democrático. Esta es, en suma, la fundamentación que descansa en la defensa de la privacidad del juez Douglas en Osborn v. United States, cuando afirmaba que el reconocimiento constitucional de amplias zonas de privacidad a salvo de cualquier intromisión externa constituye presupuesto fundacional de toda sociedad libre ${ }^{157}$. Por todo, nada mejor que concluir con los términos que utilizó el mismo juez Douglas en 1952, afirmando con él que «el derecho a ser dejado solo es el principio de toda libertad» ${ }^{158}$.

$* * *$

TitLe: The Right to Privacy at the United States: A Diachronic Approach to the Constitutional Interests at Stake

ABSTRACT: Although the federal Constitution of the United States does not expressly recognize a "right to privacy", however, the Supreme Court, over a long and gradual case law, has considered it implicit in the guarantees of the First, Fourth, Fifth, Ninth and Fourteenth Amendments. Therefore, in the American constitutional system the right to privacy is a broad concept, which is set along more than a century to progressively delimit those areas of the private sphere which tend to preserve those interests of solitude, sanctuary, autonomy, individuality, personal development, freedom of choice in personal matters, control of personal information, as well as the essential substrate of the inviolable human dignity. These essential individual interests contribute to the formation of an active and participatory citizenship, constituting thus the right to privacy a fundamental legal interest for the very existence of the democratic system.

RESUMEN: Aunque la Constitución federal de los Estados Unidos no reconoce expresamente un «derecho a la privacidad», sin embargo, el Tribunal Supremo, a lo largo de una extensa y gradual jurisprudencia, lo ha considerado implícito en las garantías de la Primera, Cuarta, Quinta, Novena y Decimocuarta Enmiendas. Por tanto, en el sistema constitucional norteamericano el derecho a la privacidad es un concepto amplio, que se ha configurado a lo largo de más de un siglo al delimitarse progresivamente aquellos ámbitos de la esfera privada que tienden a preservar esos intereses de soledad, secreto, autonomía, individualidad, desarrollo de la personalidad, libertad de elección en asuntos personales, control de la infor-

156 Orwell, G., Nineteen Eighty-Four, A novel, Secker and Warburg, London, 1949.

157 Osborn v. United States, 385 U.S. 323, 353, 354 (1966) (Douglas, J., dissenting).

158 «La Libertad en el sentido constitucional debe significar algo más que la libertad frente a restricciones gubernamentales ilegales, debe incluir también la privacidad, si se quiere que sea depositaria de la libertad. El derecho a ser dejado solo es en realidad el principio de toda libertad», Public Utilities Commission v. Pollak, 343. U.S. 451, 467 (1952)(Douglas, J., dissenting). 
mación personal, así como del sustrato esencial de la inviolable dignidad humana. Intereses individuales de carácter esencial que coadyuvan a la formación de una ciudadanía activa y participativa, constituyendo así el derecho a la privacidad un bien jurídico fundamental para la existencia misma del sistema democrático.

Key Words: American Constitutional Law. Right to Privacy. Democratic System.

Palabras Clave: Derecho constitucional norteamericano. Derecho a la privacidad. Sistema democrático.

FECHA DE RECEPCIÓN: 19.05.2011 FECHA DE ACEPTACIÓN: 29.07.2011 
